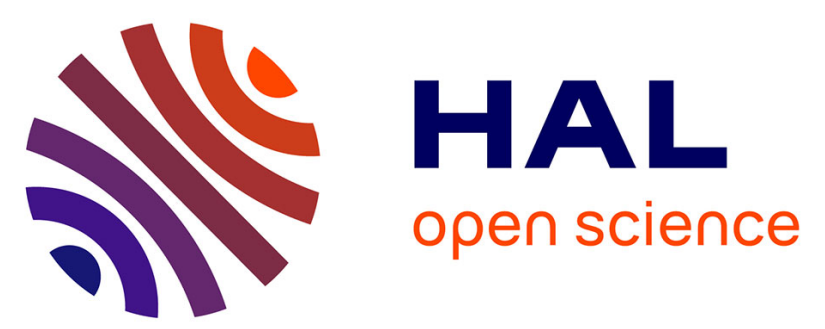

\title{
Contribution of NAD 2D-NMR in liquid crystals to the determination of hydrogen isotope profile of methyl groups in miliacin
}

Philippe Berdagué, Philippe Lesot, Jérémy Jacob, Valery T. Terwilliger, Claude Le Milbeau

\section{To cite this version:}

Philippe Berdagué, Philippe Lesot, Jérémy Jacob, Valery T. Terwilliger, Claude Le Milbeau. Contribution of NAD 2D-NMR in liquid crystals to the determination of hydrogen isotope profile of methyl groups in miliacin. Geochimica et Cosmochimica Acta, 2016, 173, pp.337-351. 10.1016/j.gca.2015.10.004 . insu-01225227

\section{HAL Id: insu-01225227 https://hal-insu.archives-ouvertes.fr/insu-01225227}

Submitted on 5 Nov 2015

HAL is a multi-disciplinary open access archive for the deposit and dissemination of scientific research documents, whether they are published or not. The documents may come from teaching and research institutions in France or abroad, or from public or private research centers.
L'archive ouverte pluridisciplinaire HAL, est destinée au dépôt et à la diffusion de documents scientifiques de niveau recherche, publiés ou non, émanant des établissements d'enseignement et de recherche français ou étrangers, des laboratoires publics ou privés.

\section{(ㅇ)(1) $\$$}

Distributed under a Creative Commons Attribution - NonCommercial - NoDerivatives| 4.0 


\section{Accepted Manuscript}

Contribution of NAD 2D-NMR in liquid crystals to the determination of hydrogen isotope profile of methyl groups in miliacin

Philippe Berdagué, Philippe Lesot, Jérémy Jacob, Valery J. Terwilliger, Claude Le Milbeau

PII:

S0016-7037(15)00586-4

DOI: http://dx.doi.org/10.1016/j.gca.2015.10.004

Reference: GCA 9458

To appear in:

Geochimica et Cosmochimica Acta

Received Date: $\quad 20$ February 2015

Accepted Date: $\quad 6$ October 2015

Please cite this article as: Berdagué, P., Lesot, P., Jacob, J., Terwilliger, V.J., Milbeau, C.L., Contribution of NAD 2D-NMR in liquid crystals to the determination of hydrogen isotope profile of methyl groups in miliacin, Geochimica et Cosmochimica Acta (2015), doi: http://dx.doi.org/10.1016/j.gca.2015.10.004

This is a PDF file of an unedited manuscript that has been accepted for publication. As a service to our customers we are providing this early version of the manuscript. The manuscript will undergo copyediting, typesetting, and review of the resulting proof before it is published in its final form. Please note that during the production process errors may be discovered which could affect the content, and all legal disclaimers that apply to the journal pertain. 


\title{
Contribution of NAD 2D-NMR in liquid crystals to the determination of hydrogen isotope profile of methyl groups in miliacin
}

\author{
Philippe Berdagué, a,b $^{\text {, Philippe Lesot }}{ }^{\mathrm{a}, \mathrm{b}^{*}}$, Jérémy Jacob $^{\mathrm{c}, \mathrm{d}, \mathrm{e}}$, Valery J. Terwilliger ${ }^{\mathrm{c}, \mathrm{d}, \mathrm{e}, \mathrm{f}, \mathrm{g}}$ \\ and Claude Le Milbeau ${ }^{\mathrm{c}, \mathrm{d}, \mathrm{e}}$ \\ ${ }^{a} R M N$ en Milieu Orienté, ICMMO, UMR CNRS 8182, Université de Paris-Sud, Université Paris-Saclay, Bât. 410, \\ 91405 Orsay cedex, France. \\ ${ }^{b}$ CNRS/INC, ICMMO, UMR 8182, 91405 Orsay cedex, France. \\ 'Université d'Orléans, ISTO, UMR 7327, 45071, Orléans, France. \\ ${ }^{d}$ CNRS/INSU, ISTO, UMR 7327, 45071 Orléans, France. \\ ${ }^{e} B R G M, I S T O, U M R$ 7327, BP 36009, 45060 Orléans, France. \\ ${ }^{f}$ LE STUDIUM ${ }^{\circledR}$, Loire Valley Institute for Advanced Studies, France. \\ ${ }^{g}$ Department of Geography, University of Kansas, Lawrence, KS 66045, USA.
}

\begin{abstract}
The hydrogen isotopic composition $(\delta \mathrm{D}$ or $(\mathrm{D} / \mathrm{H})$ value) of molecular biomarkers preserved in sedimentary archives is increasingly used to provide clues about the evolution of past climatic conditions. The rationale is that intact biomarkers retain isotopic information related to the climatic conditions that prevailed at the time of their synthesis. Some of these biomarkers may be degraded during diagenesis, however. The extent to which these degradations alter the original $\delta \mathrm{D}$ value of the source biomarker is presently debated and the capacity to resolve the debate by determinations of compound-specific $\delta \mathrm{D}$ values alone is limited. The "bulk" or "global" $\delta \mathrm{D}$ value of any molecule is in fact a composite of $\delta \mathrm{D}$ values at each site within this molecule $\left(\left(\delta \mathrm{D}_{\mathrm{i}}\right.\right.$ or $(\mathrm{D} / \mathrm{H})_{\mathrm{i}}$ with $\mathrm{i}=$ number of hydrogen/deuterium atoms in the considered molecule). Determination of this site-specific $\delta \mathrm{D}_{\mathrm{i}}$ value in biomarkers could not only yield outstanding paleoenvironmental information but also help forecast the impacts of diagenesis and define essential steps in biosynthetic pathways.

This task is analytically challenging. Here, we examined the capabilities of natural abundance deuterium 2D-NMR (NAD 2D-NMR) using homopolypeptide liquid crystals as an NMR solvent to: i) analyze the NAD spectra of biomakers; ii) determine the site-specific distribution of hydrogen in the nine methyl groups ( $\delta \mathrm{D}_{\text {Mei }}$ with $\mathrm{i}=23$ to 31 ) of miliacin, a pentacyclic triterpene of the amyrin family and key biomarker for broomcorn millet in sedimentary archives. Relative $(\mathrm{D} / \mathrm{H})_{\mathrm{Mei}}$ values-were established by anisotropic NAD 2D-NMR. Then absolute $\delta \mathrm{D}_{\text {Mei }}$ values were obtained by determining $\delta D_{\text {Mei }}$ value of the methoxy group of miliacin using two independent approaches: isotropic NAD NMR (SNIF-NMR ${ }^{\mathrm{TM}}$ ) and GC-irMS. The resulting isotope profile for miliacin shows, for the first time, large variations in $\delta \mathrm{D}_{\text {Mei }}$ values that can directly be explained by biosynthetic processes. This approach has also the potential to permit predicting fractionations during pentacyclic triterpene diagenesis.
\end{abstract}

Corresponding author: Dr. Philippe Lesot

Address: RMN en Milieu Orienté, ICMMO, UMR CNRS 8182, Université de Paris-Sud, 91405

Orsay cedex, France, Tel.: +33 (0) 1691547 59, Fax: +33 (0) 169158105

E-mail address: philippe.lesot@u-psud.fr (Philippe Lesot)

Keywords: Deuterium NMR, Isotope profile, Site-specific, Natural abundance, Miliacin, Pentacyclic triterpene, Liquid crystal, Biosynthesis, Diagenesis

Type of article: Research article

Supplementary information: Yes 


\section{INTRODUCTION}

Higher plant pentacyclic triterpenes are natural products that bear an oxygenated group at the C-3 position (Fig. 1). The large diversity of structures, isomerisms and functional groups resulting from specific enzymatic processes have led to the use of compounds in this family for establishing precise chemotaxonomic relationships (Das and Mahato, 1983; Mahato et al., 1992; Mahato and Sen, 1997). Although $\beta$ - and $\alpha$-amyrins are very common structures in angiosperms, several classes of compounds are more or less specific to given taxa. For example, pentacyclic triterpenes with an acetate function at C-3 are largely restricted to Asteraceae species (Lavrieux et al., 2011) whereas those bearing a methoxy group at the C-3 position are mostly synthetized by Poaceae (Ohmoto et al., 1970; Jacob et al., 2005). After the death of their source organisms, these compounds may be archived in geological deposits such as soils or sediments. If diagenesis does not strongly modify their structure, these compounds can be analyzed for presence/absence and concentrations in sedimentary records in order to reconstruct past vegetation dynamics (e.g., Cranwell et al., 1984; Killops et al., 1995; van Aarsen et al., 2000; Regnery et al., 2013).

$3 \beta$-methoxyolean-18-ene, usually denoted miliacin or germanicol methyl ether (Fig. 1), is such a specific molecular biomarker. It is a pentacyclic triterpene bearing a methoxy group at position C-3 that is predominantly produced by Poaceae species. Furthermore, this compound is most abundant in broomcorn millet (Panicum miliaceum L) (Itô et al., 1934; Ohmoto et al., 1970; Bossard, 2013). Miliacin concentrations in lake sediments and soils have thus been used to reconstruct the history of millet cultivation (Jacob et al., 2008, 2008b, 2009; Simonneau et al., 2013; Motuzaite-Matuceviciute et al., 2013).

In addition to these crucial information on past vegetation, the hydrogen isotopic compositions $(\delta \mathrm{D}$ or $\mathrm{D} / \mathrm{H})$ of lipid compounds, such as miliacin, in geological deposits are providing superior insights about paleoclimate (Sachse et al., 2012; Terwilliger et al., 2013; Terwilliger and Jacob, 2013). This is because meteoric water is the original source of hydrogen atoms in biochemicals produced by autotrophs and the $\delta \mathrm{D}$ values of meteoric water are strongly influenced by climate (Dansgaard et al., 1964; Gat et al., 1996). Further studies are needed in order to fully exploit the paleoclimate potential of $\delta \mathrm{D}$ values of lipid compounds for providing clues about past climates, with distinct levels of understanding on the processes occurring at different steps (Sachse et al., 2012). The impacts of environmental factors such as soil evaporation and leaf transpiration are relatively well identified. Leaf transpiration can alter the $\delta D$ value of meteoric water along its path to the sites of photosynthesis where its hydrogen atoms from leaf water will be used to produce organic compounds via biosynthetic pathways (Sessions et al., 1999; Chikaraishi and Narakoa, 2003; Hou et al., 2007b; McInerney et al., 2011). Additionally, it has been demonstrated that plant type can cause differences in $\delta \mathrm{D}$ values of the most common lipid compounds such as $n$-alkyl lipids (Sachse et al., 
2006; Liu et al., 2006; Smith and Freeman, 2006; Hou et al., 2007; Feakins and Sessions, 2010; Wang et al., 2013). Because it would not be affected by variations caused by differences in plantsource taxa, the $\delta D$ value of more specific compounds such as sedimentary miliacin is expected to solve this issue and could provide even higher resolution information about climatic conditions at the time of their synthesis (Bossard et al., 2011; Bossard, 2013; Terwilliger et al., 2013; Schwab et al., 2015). A better understanding of the biosynthetic pathway that designs the $\delta D$ values of a given compound is also necessary since distinct NADPH sources and enzymatic processes can lead to highly variable fractionations (i.e. Sauer et al., 2001; Chikaraishi et al., 2004, 2009). Although the biosynthetic pathway of pentacyclic triterpenes such as miliacin is rather well known (Xu et al., 2004), associated H isotopic fractionations are less understood.

Finally, it is crucial to determine whether diagenetic derivatives retain the original paleoclimate information acquired by biochemicals during biosynthesis. For instance, pentacyclic triterpenes can undergo several transformations during early diagenesis such as the loss of functional groups, the loss of rings, double bond migration, aromatization, or epimerization of methyl groups (Corbet, 1980; Trendel, 1985; Lohmann, 1988; Jacob et al., 2007). Only isotopic exchanges with water have been addressed on polycyclic compounds (Wang et al., 2013) but the impact of diagenetic transformations on $\delta \mathrm{D}$ values of diagenetic by-products compared to their precursors is yet unknown.

Our hypothesis is that a site-specific (or intramolecular) heterogeneous distribution of hydrogen isotopes in a biochemical precursor would explain any isotopic difference with its derivatives caused by the preferential loss of D-enriched or D-depleted groups during diagenesis. Identifying such isotopic difference between biochemicals and their diagenetic derivatives will allow better climate reconstructions from $\delta \mathrm{D}$ values of diagenetic derivatives. In addition, obtaining the site-specific distribution of hydrogen isotopes could provide useful information on biosynthetic pathways. As emphasized by Eglinton and Eglinton (2008), “intramolecular compound-specific isotope measurements (i.e., analyses of the distribution of isotopes within a molecular structure) are analytically challenging and presently rarely attempted, but may ultimately prove of value" and so addressing this hypothesis requires the development of new tools.

The two main objectives of our study were to test the hypothesis that hydrogen isotopes are not randomly distributed in molecular biomarkers and to identify the means of analyzing the site-specific distribution of hydrogen isotopes necessary for this test. We use miliacin as a representative of pentacyclic triterpenes. Specifically, we determined the $(\mathrm{D} / \mathrm{H})$ ratios $(\delta \mathrm{D})$ of hydrogen located in the methyl groups of miliacin by Natural Abundance Deuterium (NAD), two-dimensional Nuclear Magnetic Resonance (2D-NMR) spectroscopy using aligning organic media (anisotropic systems) as NMR solvents. This advanced technique modifies the well-known SNIF-NMR ${ }^{\mathrm{TM}}$ method pioneered 
by Martin and co-workers in the 80's (Martin et al., 1980; 1986) by dissolving the analyte in a liquid crystal (LC) instead of a liquid solvent (isotropic system). The replacement of isotropic to oriented solvent is analytically highly valuable because we have access to ${ }^{2} \mathrm{H}$ residual quadrupolar couplings in solutes, leading to the presence on ${ }^{2} \mathrm{H}$ NMR spectra of quadrupolar doublets (QD) for each inequivalent deuteron instead of singlets. The range of splittings of each QD leads in turn to distribute the NAD signals on larger spectral windows, thus reducing the peak overlaps. Concomitantly the use of 2D-NMR experiments simplifies the analysis of entangled, overcrowded anisotropic NAD 1D-NMR spectra. As we will see, this approach makes it possible to distinguish several NAD signals from $\mathrm{H}$ in methyl groups of miliacin that resonated at the same (or very close) frequencies in isotropic solvents. This unusual strategy has been recently pioneered by Lesot and coworkers for analyzing the site-specific isotope ratios, $(\mathrm{D} / \mathrm{H})_{\mathrm{i}}$, in fatty acids and then triglycerides (Lesot et al., 2008, 2009, 2011, 2012; Serhan et al., 2010). We report here its first application for investigating biomarkers of interest such as miliacin.

\section{ANISOTROPIC ${ }^{2}$ H NMR SPECTROSCOPY}

When a molecule in the spectrometer's magnetic field does not tumble isotropically, all orientation-dependent NMR interactions become visible on spectra. Thus ${ }^{2} \mathrm{H}$ NMR spectra of solutes in a mesophase contains new informative NMR interactions such as the chemical shift anisotropy $\left({ }^{2} \mathrm{H}\right.$ CSA); ii) the dipolar interactions (D); iii) and the quadrupolar interaction (I $\geq 1$ ) (Sarfati et al., 2000; Lesot et al., 2015) (isotopically normal or enriched).

Assuming that ${ }^{2} \mathrm{H}$ CSA is generally negligible while the ${ }^{2} \mathrm{H}-{ }^{1} \mathrm{H}$ couplings can be removed by ${ }^{1} \mathrm{H}$ decoupling, the ${ }^{2} \mathrm{H}$ signal of aligned monodeuterated molecule is a simple QD (two transitions) centered on the anisotropic ${ }^{2} \mathrm{H}$ chemical shift, $\delta\left({ }^{2} \mathrm{H}\right)^{\text {aniso }}$, (generally $\left.\delta\left({ }^{2} \mathrm{H}\right)^{\text {aniso }} \approx \delta\left({ }^{2} \mathrm{H}\right)^{\text {iso }}\right)$ (Lesot et al., 2009). The separation (in $\mathrm{Hz}$ ) between components of doublet is referred to as ${ }^{2} \mathrm{H}$ quadrupolar splitting (or the residual quadrupolar coupling) and will be noted $\Delta v_{Q_{i}}{ }^{2} \mathrm{H}$ ) therein (Fig. S-4, Appendix A.II). For a C-D internuclear directions oriented in a weakly-aligning LC, the electric field gradient $\left(\mathrm{V}_{\mathrm{C}-\mathrm{D}}\right)$ is usually assumed to be axially symmetric along the $\mathrm{C}-\mathrm{D}$ vector and the value of $\Delta v_{\mathrm{Qi}}$ relative to the $\mathbf{B}_{\mathbf{0}}$ can be expressed as (Eq. 1; Sarfati et al., 2000; Lesot et al., 2009): where $\mathrm{C}_{\mathrm{Q}}^{\mathrm{D}_{\mathrm{i}}}$ is the quadrupolar coupling constant at deuterium atom $\mathrm{i}, \mathrm{S}_{\mathrm{C}-\mathrm{Di}}$, is the order parameter of the $\mathrm{C}-\mathrm{D}_{\mathrm{i}}$ vector and $\theta_{C-D_{i}}$ is the angle between the $\mathbf{B}_{\mathbf{o}}$ magnetic field axis and the $\mathrm{C}-\mathrm{D}_{\mathrm{i}}$ bond axis.

$$
\Delta v_{\mathrm{Q}}=\frac{3}{2} \mathrm{C}_{\mathrm{Q}}^{\mathrm{D}_{\mathrm{i}}} \times \mathrm{S}_{\mathrm{C}-\mathrm{D}_{\mathrm{i}}}=\frac{3}{2}\left(\frac{\mathrm{eQ}_{\mathrm{D}_{\mathrm{i}}} \mathrm{V}_{\mathrm{C}-\mathrm{D}_{\mathrm{i}}}}{\mathrm{h}}\right) \times\left(\frac{1}{2}\left\langle 3 \cos ^{2}\left(\theta_{\mathrm{C}-\mathrm{D}_{\mathrm{i}}}\right)-1\right\rangle\right)
$$

55 The $\langle\cdots\rangle$ denotes an ensemble average. As the trigonometric function in brackets varies between 1 
(when $\theta_{{\mathrm{C}-\mathrm{D}_{\mathrm{i}}}} / / \mathbf{B}_{\mathbf{o}}$ ) and -0.5 (when $\theta_{{\mathrm{C}-\mathrm{D}_{\mathrm{i}}}} \perp \mathbf{B}_{\mathbf{0}}$ ), $\Delta v_{\mathrm{Qi}}$ can be positive or negative. When $\theta_{\mathrm{C}-\mathrm{D}_{\mathrm{i}}}$ is equal to $54.7^{\circ}$ (the so-called 'magic angle'), $S_{\mathrm{C}-\mathrm{Di}}$ becomes null, and so the doublet collapses to a single line.

As the second stable isotope of hydrogen, deuterium atoms are naturally in all organic compounds, and hence they can be used as nuclear probe to study the site-specific natural isotope distribution of molecules. Even with low natural abundance of deuterons (around $1.5510^{-2} \% \mathrm{~V}$ SMOW value; De Laeter et al., 2003), routine NMR spectrometers can detect quite easily (with reasonable experimental times) their NMR signals both in isotropic and anisotropic solvents, successful results depending also on the concentration of the analyte and its molecular weight (Lesot et al., 1998, 2009).

Proton-decoupled NAD NMR spectra of solutes dissolved in homogeneous mesophases consist of a sum of resolved independent quadrupolar doublets instead of single lines as in liquids, each of them corresponding to the various inequivalent ${ }^{2} \mathrm{H}$ sites in the molecule. For middle to largesized molecules, the distribution of positions and the splitting of ${ }^{2} \mathrm{H}$ doublets over the spectral window can generate complex spectra (with possible overlaps of resonances), where the assignment of QD can be ambiguous. Various two and three-dimensional (2D/3D) NMR sequences belonging to NMR experiment class entitled "QUadrupole Ordered SpectroscopY" (QUOSY) have been specifically developed to achieve clearer analyses of overcrowded anisotropic NAD 1D spectra (Merlet et al, 1999; Lesot and Lafon, 2008b). All of them allow the spectral information $\left(\delta, \Delta v_{\mathrm{Q}}\right)$ to be distributed on several (two or three) spectral dimensions $\left(F_{1}, F_{2}\right.$ and $\left.F_{3}\right)$, thus facilitating the assignment of ${ }^{2} \mathrm{H}$ quadrupolar doublets.

\section{ANALYTES, MATERIALS AND METHOD}

\subsection{Structure of miliacin and germanicol}

Like other pentacyclic triterpenes, miliacin is formed from mevalonic acid via the mevalonate pathway through the cyclisation of squalene epoxide by an oxidosqualene cyclase (Xu et al., 2004; see Section 6). This scheme leads to the formation of germanicol, a triterpene alcohol constituted of five six-membered rings (Fig. 1) that bear eight methyl groups (Me23 to Me30). The final conversion of the alcohol function into a methyl ether function, which principally takes place in plants of the family Poaceae (Jacob et al., 2005), transforms germanicol into miliacin, by the addition of a methyl group (Me31) linked to the oxygen on the C-3 position. In miliacin, the nine methyl groups are numbered from Me23 to Me31 (Fig. 1). For simplicity, the five 6-membered rings of miliacin have been labeled A-E and contain two or three methyl groups each (ring A: Me23, Me24 and Me 25; ring C: Me26 and Me27; ring E: Me28, Me29 and Me30). 


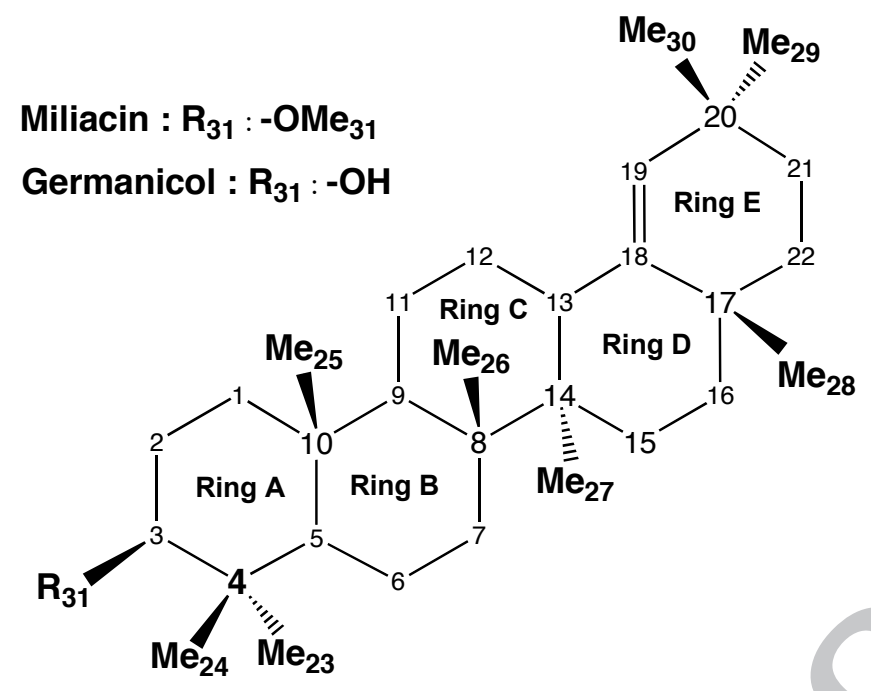

Figure 1: Structure of miliacin where $\mathrm{R}_{31}=-\mathrm{OMe}$ and germanicol where $\mathrm{R}_{31}=-\mathrm{OH}$, together with the atomic numbering used and notation of rings (A to E) and methyl groups (23 to 31).

\subsection{Miliacin and germanicol extraction and purification}

Miliacin and germanicol were recovered from millet oil (provided by HITEX, Vannes, France) of > 98\% purity as determined by Gas Chromatography/Mass Spectrometry (GC/MS). 6 g of miliacin were directly recovered from $750 \mathrm{ml}$ of oil by repeated precipitation in cold acetone (Itô, 1934). From these $6 \mathrm{~g}$ of analyte, only about $100 \mathrm{mg}$ of miliacin was necessary to prepare NMR samples used for NAD NMR analyses described in this work. Germanicol, which is far less abundant than miliacin in the oil, was recovered from a longer process of separating the oil into neutral, acidic and polar fractions by Solid Phase Extraction using aminopropyl bonded silica (Jacob et al., 2005). The neutral fraction was recovered by elution with $\mathrm{CH}_{2} \mathrm{Cl}_{2}$ : isopropanol (9:1) and further separated on activated silica $\left(120^{\circ} \mathrm{C}\right.$ during $24 \mathrm{~h}$ ) deactivated with $5 \%$ weight water. After elution of aliphatic hydrocarbons, aromatics, esters and ether, and ketones, the alcohol fraction that contains germanicol was eluted with $2 \mathrm{ml}$ of hexane:ethyl acetate (85:15) and then $2 \mathrm{ml}$ of hexane:ethyl acetate (80:20) as described by Jacob et al. (2008b). To eliminate the large amounts of sitosterol that coelutes with germanicol, we then separated the alcohol fraction on activated silica by splitting the alcohol fraction into sub-fractions of $500 \mu 1$ of hexane:ethyl acetate (85:15). After GC/MS analysis of an acetylated aliquot of these sub-fractions, we combined fractions containing germanicol.

\subsection{Miliacin and germanicol $\delta \mathrm{D}$ values by $\mathrm{GC}$-irMS}

Germanicol was acetylated into germanicol acetate with acetic anhydride and pyridine (1:1) during $1 \mathrm{~h}$ at $80^{\circ} \mathrm{C}$ prior to its GC-irMS analysis. Acetic anhydride with an offline-determined $\delta \mathrm{D}$ value of $-133 \pm 2 \%$ was acquired from A. Schimmelmann (Indiana University, USA). After drying under nitrogen, the fraction was dissolved in isooctane prior to analysis by Gas Chromatographyisotope ratio Mass Spectrometry (GC-irMS) in order to determine its $\delta \mathrm{D}$ value. Miliacin from the $6 \mathrm{~g}$ 
in-house stock was also dissolved in isooctane prior to GC-irMS analysis.

$\delta D$ values were determined on a TraceGC chromatograph equipped with a Triplus Autosampler coupled to a DeltaV Advantage isotope ratio mass spectrometer through a GC-Isolink interface and a Conflo IV dilution system (all from Thermo Scientific, Bremen, Germany). The gas chromatograph was fitted with a TG5-MS capillary column $(60 \mathrm{~m}, 0.25 \mathrm{~mm}$ i.d., $0.25 \mu \mathrm{m}$ film thickness; ThermoScientific). The temperature of the column was held at $80^{\circ} \mathrm{C}$ for $1 \mathrm{~min}$, and then increased from 80 to $300^{\circ} \mathrm{C}$ at $20^{\circ} \mathrm{C} \cdot \mathrm{min}^{-1}$, with a final isothermal hold at $300^{\circ} \mathrm{C}$ for $30 \mathrm{~min}$. Precision and accuracy were determined by using a mixture of $15 n$-alkanes $\left(n-\mathrm{C}_{16}\right.$ to $\left.n-\mathrm{C}_{30}\right)$ with $\delta \mathrm{D}$ values ranging from -9 to $-254 \%$ determined off-line (A5 mixture, A. Schimmelmann, Indiana University, USA) and allowed us to normalize the $\delta \mathrm{D}$ values of miliacin $\left(\delta \mathrm{D}_{\text {miliacin }}\right)$ and of germanicol $\left(\delta \mathrm{D}_{\text {germanicol }}\right)$ to the $\mathrm{V}$-SMOW isotopic scale. The measured $\delta \mathrm{D}$ values for the standard $n$-alkanes are in good agreement with those measured off-line $\left(\mathrm{r}^{2}=0.987\right)$. The overall precision for the $\mathrm{n}$-alkanes standards was $\leq 4 \%$. Samples were injected at least three times and were accurate to $\pm 5 \%$ for miliacin and germanicol. The $\delta \mathrm{D}$ value of germanicol acetate was mathematically corrected from the contribution of acetic anhydride to obtain the $\delta \mathrm{D}_{\text {germanicol }}$ value. Our results are shown as both $(\mathrm{D} / \mathrm{H})$ ratios in ppm and $\delta \mathrm{D}$ values in $\%$, calculated using a $(\mathrm{D} / \mathrm{H})$ value of $\mathrm{V}-\mathrm{SMOW}$ of $155.76 \pm 0.05 \mathrm{ppm}$, and converting from ppm values to \%o values using Equation 2:

$$
\delta \mathrm{D}=\left(\frac{(\mathrm{D} / \mathrm{H})_{\mathrm{i}}}{(\mathrm{D} / \mathrm{H})_{\mathrm{V}-\mathrm{SMOW}}}-1\right) \times 1000
$$

\subsection{Isotropic ${ }^{1} \mathrm{H}$ and ${ }^{13} \mathrm{C}$ NMR of miliacin}

The full assignment of the proton and carbon-13 signals recorded in liquid solvents $\left(\mathrm{CDCl}_{3}\right)$ was achieved using homonuclear ${ }^{1} \mathrm{H}-{ }^{1} \mathrm{H}$ 2D COSY, heteronuclear ${ }^{13} \mathrm{C}-{ }^{1} \mathrm{H} \mathrm{HMBC}$ and HMQC $2 \mathrm{D}$ experiments combined with the analysis of ${ }^{13} \mathrm{C}-{ }^{13} \mathrm{C}$ ADEQUATE 2D spectrum. Several isotropic NMR spectra of miliacin are given in Figs. S-1, S-2 and S-3 in Appendix A.II. All isotropic NMR data were recorded on a Bruker 9.4 T (400 MHz) Advance I spectrometer equipped with $5 \mathrm{~mm}$ o.d. BBI probe.

\subsection{Preparation of polypeptide oriented samples}

The ability to solubilize a given analyte but also to form a polypeptidic homogeneous liquidcrystalline phase is an important factor that depends on what organic co-solvent is chosen. We were best able to solubilize miliacin using $30 \mathrm{mg}$ of miliacin, $80 \mathrm{mg}$ of poly- $\gamma$-benzyl- $L$-glutamate (PBLG) with a degree of polymerization of 743 (MW (viscosity) = $162900 \mathrm{~g} / \mathrm{mol}$ ) and $810 \mathrm{mg}$ of chloroform, corresponding to $8.7 \% \mathrm{w} / \mathrm{w}$ (PBLG) and $3.2 \% \mathrm{w} / \mathrm{w}$ (miliacin). Over this latter mass ratio, miliacin is not totally dissolved in the mesophase, and solid particles are visible, even at higher temperatures. Other polar and apolar organic solvents that we experimented and that proved less 
satisfactory include $\mathrm{CH}_{2} \mathrm{Cl}_{2}$, tetrachloroethane, THF, dioxane, pyridine. For all of them, the solubility of miliacin was found to be extremely low. Note that even DMSO (incompatible with PBLG) is not suitable.

As the polypeptide is chiral, oriented solutions of PBLG is able to discriminate between NMR signals of enantiomers of wide range of organic molecules but also enantiotopic directions in prochiral compounds (Lesot et al., 2000, 2009). Nevertheless, in this work, PBLG was selected not for its enantiodiscrimining properties, which are useless for miliacin (enantiopure biocompound), but for its ability to homogeneously orient a guest molecule with a rather low degree of alignment (Lesot et al., 2000).

Due to the high molecular weight $(\mathrm{MW}=440.7 \mathrm{~g} / \mathrm{mol})$ and the small amount of miliacin that can be solubilized in the $\mathrm{PBLG} / \mathrm{CHCl}_{3}$ mesophase (only $30 \mathrm{mg}$ ), the molar amount in monodeuterated isotopomers is equal to $3.17 \times 10^{-8}$ mol for methyl groups and $1.06 \times 10^{-8}$ mol for methines, if $(\mathrm{D} / \mathrm{H})=1.55 \times 10-2 \%$. Assuming that density of the mixture is equal to 1 , the concentration of isotopomers in the sample at methyl and methine sites is evaluated at about 3.4 $\mu \mathrm{mol} / \mathrm{l}$ and $1.14 \mu \mathrm{mol} / \mathrm{l}$, respectively. This isotopomeric concentration is weak (30 fold less) compared to the value of chloroform. However recording anisotropic NAD spectra of solute with rather short recycling delays $\left(\mathrm{T}_{\mathrm{R}}=1 \mathrm{sec}\right)$ allows to significantly reduce the intensity of ${ }^{2} \mathrm{H}$ signal of $\mathrm{CDCl}_{3}$ (and avoid a bad digitization of solute signals) whereas quantitative conditions $\left(\mathrm{T}_{\mathrm{R}}=5 \mathrm{~T}_{1}\left({ }^{2} \mathrm{H}\right)\right.$ ) were maintained to record the ${ }^{2} \mathrm{H}$ signals of miliacin (Lesot et al., 2008).

\subsection{Anisotropic NAD 2D-NMR in LC}

All anisotropic NAD 2D-NMR spectra were recorded with a $14.1 \mathrm{~T}$ Bruker Advance II spectrometer (92.1 $\mathrm{MHz}$ for deuterium nuclei) equipped with a $5 \mathrm{~mm}$ o.d. selective ${ }^{2} \mathrm{H}$ cryogenic probe. NAD $Q$-resolved Fz 2D experiments combined with proton Waltz-16 decoupling sequence was chosen to analyze of NAD NMR spectra of miliacin dissolved in PBLG/ $\mathrm{CHCl}_{3}$ (Lafon et al., 2009). In this experiment, the ${ }^{2} \mathrm{H}$ chemical shifts are refocused in the $F_{1}$ dimension. After a double FT, the 2D map can be tilted (see the principle on Figure S-5 in Appendix A.II), and then symmetrized, thereby spreading the ${ }^{2} \mathrm{H}$ chemical shifts, $\delta\left({ }^{2} \mathrm{H}\right)$, and quadrupolar splittings, $\Delta v_{\mathrm{Q}}\left({ }^{2} \mathrm{H}\right)$ information in the $F_{2}$ (horizontal axis) and $F_{1}$ (vertical axis) dimensions, respectively. Thus a series of ${ }^{2} \mathrm{H}$ singlets are displayed in $F_{2}$ whilst a series of independent ${ }^{2} \mathrm{H}$ doublets are observed in $F_{1}$.

The anisotropic $Q$-resolved Fz 2D spectra were recorded using a 2D matrix of $2652\left(t_{1}\right) \times 300$ $\left(\mathrm{t}_{2}\right)$ data points, then zerofilled to $4096\left(t_{1}\right) \times 1024\left(t_{2}\right)$ data points prior the double FT. 256 scans were added at each $t_{1}$ increment. A lorenzian filtering was applied in both dimensions $(\mathrm{LB}=1.5 \mathrm{~Hz})$. The recycling delay $\left(T_{R}\right)$ of anisotropic NAD 2D experiments was set to $1 \mathrm{sec}$, leading to a total acquisition time of 24 hours. Such a delay is large enough to record the anisotropic NAD spectrum 
of miliacin with quantitative conditions and reliable evaluation of peak integrals (on 1D spectra) or 2D volume on 2D spectra of miliacin is then possible (Lesot et al., 2008). "Integral of two components of NAD doublets measured on 1D traces extracted to 2D maps (see below and sup info) were determined by peak deconvolution (Top-spin 3.0 software)“. To improve the accuracy of the measure of $(\mathrm{D} / \mathrm{H})$ ratios and evaluate the standard deviation, six identical NAD 2D-NMR experiments on the same NMR sample of miliacin were recorded and analysed.

\subsection{SNIF-NMR ${ }^{\mathrm{TM}}$ protocol and experimental details}

According to the SNIF-NMR protocol, isotropic NAD 1D-NMR spectra of analytes are recorded under quantitative conditions $\left(T_{R}=5 T_{1}\right)$ with internal isotopic reference whose $D / H$ ratio is calibrated. If the mass of compounds (analyte and reference) is accurately weighted, the site-specific $(\mathrm{D} / \mathrm{H})_{\mathrm{i}}$ ratios (expressed in $\mathrm{ppm}$ ) can be calculated from evaluation of peaks surface on NMR spectra as follows (Eq. 3; Lesot et al., 2011; Martin et al., 1986):

$$
(D / H)_{i}^{\text {anal }}=\left(\frac{A_{i}^{\text {anal }}}{A_{i}^{\text {ref }}}\right) \times\left(\frac{P_{i}^{\text {ref }} \times m^{\text {ref }} \times M^{\text {anal }}}{P_{i}^{\text {anal }} \times m^{\text {anal }} \times M^{\text {ref }}}\right) \times(D / H)_{i}^{\text {ref }}
$$

In Eq. 3, $\mathrm{A}_{\mathrm{i}}^{\text {anal }}$ and $\mathrm{A}_{\mathrm{i}}^{\text {ref }}$ are the areas of the signals at site $\mathrm{i}$ for the analyte and the reference, $\mathrm{P}_{\mathrm{i}}^{\text {anal }}$ and $\mathrm{P}_{\mathrm{i}}^{\text {ref }}$ are their stoichiometric numbers of hydrogen at site $i, M^{\text {anal }}, M^{\text {ref }}, m^{\text {anal }}$ and $m^{\text {ref }}$ are the molecular weights and masses of the analyte and the reference, respectively. Finally, $(\mathrm{D} / \mathrm{H})_{\mathrm{i}}^{\mathrm{ref}}$ is the isotope ratio of reference (at site i).

From the experimental conditions viewpoint, the SNIF-NMR 1D spectrum of miliacin was recorded in chloroform in the presence of isotopically calibrated tetramethyl urea (TMU) as internal chemical reference $\left((\mathrm{D} / \mathrm{H})_{\mathrm{TMU}}=84.4 \pm 2 \mathrm{ppm}\right.$, Lot 0116XAC from Eurofins). The temperature of $305 \mathrm{~K}$ used provided a good compromise between a reasonable experimental time for the NAD 1D experiments $(<15 \mathrm{~h})$ and a full solubilization of miliacin. At $305 \mathrm{~K}$, the $\mathrm{T}_{1}\left({ }^{2} \mathrm{H}\right)$ of TMU was measured at $1.17 \mathrm{sec}$ (average of three NAD inversion-recovery 1D-NMR experiments), leading to a recycling delay, $T_{R}$, of $6 \mathrm{sec}$ (with $3.5 \mathrm{sec}$ of acquisition time) and in turns to a total acquisition time of 15 hours for 9000 scans added. Six experiments were recorded with 6k data points (zerofilled to $16 \mathrm{~K})$, filtered by an exponential function $(1 \mathrm{~Hz})$ prior FT and peak integral for Me31 and TMU signal were quantified by peak deconvolution after a baseline correction.

The mixture was prepared in a small flask tube by adding $39.9 \mathrm{mg}$ of miliacin and $18.6 \mathrm{mg}$ of TMU (MW = 116.16 g. $\left.\mathrm{mol}^{-1}\right)$ and $1.640 \mathrm{~g}$ of dry $\mathrm{CHCl}_{3}$. The flask was then actively mixed (by strongly shaking) prior to a part of mixture $(\approx 700 \mathrm{mg}$; this amount is optimized for the length of the coil in cryogenic probe) was transferred into the 5-mm NMR tube. The tube has been fire-sealed to avoid long-term solvent evaporation. Due to the low solubility of miliacin in $\mathrm{CHCl}_{3}$, the sample was 
prepared with larger amounts of components in order to reduce the error on the weightings of small masses. Also, the mass of TMU used (twelve deuterium equivalent sites) was calculated to reach a ratio in peak intensity of TMU and Me31 (three deuterium equivalent sites) equal to about 4 , thus optimizing the $\mathrm{S} / \mathrm{N}$ ratio of TMU.

\section{RESULTS}

\subsection{Spectral assignment of isotropic ${ }^{1} \mathrm{H}$ and ${ }^{13} \mathrm{C}$ resonances}

In order to avoid any misinterpretation of the isotopic profile of methyl groups on miliacin, we re-examined the assignment of ${ }^{1} \mathrm{H}$ signals in combination with ${ }^{13} \mathrm{C}$ signals before analyzing NAD $2 \mathrm{D}$ spectra in oriented solvent and then evaluating the site-specific isotope distribution. Fig. 2 gives the $600 \mathrm{MHz}{ }^{1} \mathrm{H}$ spectrum of miliacin dissolved in chloroform at $295 \mathrm{~K}$. Due to the presence of several stereogenic centers (asymmetric carbons), the geminal protons in $\mathrm{CH}_{2}$ groups and the gemdimethyl groups are diastereotopic, and hence yield distinct ${ }^{1} \mathrm{H}$ (and also ${ }^{2} \mathrm{H}$ ) signals. The protondecoupled carbon-13 1D spectrum $\left({ }^{13} \mathrm{C}-\left\{{ }^{1} \mathrm{H}\right\}\right)$ as well as ${ }^{13} \mathrm{C} /{ }^{1} \mathrm{H}$ heteronuclear HSQC and HMBC 2D spectra of miliacin dissolved in chloroform at $295 \mathrm{~K}$ and recorded at $9.4 \mathrm{~T}$ (100 MHz) (Fig. S-1)

(Figs. S-2 and S-3) are presented in Appendix A.II. The combined analysis of all spectral data allows an unambiguous assignment of all ${ }^{13} \mathrm{C}$ and ${ }^{1} \mathrm{H}$ resonances. The full assignment of ${ }^{13} \mathrm{C}$ and ${ }^{1} \mathrm{H}$ signals is listed in Tables S-1, S-2 and S-3 in Appendix A.I. Note here that our assignment agrees with Smetanina et al. (2001), but the two ambiguities pointed out by these authors have been eliminated (Fig. S-5 in Appendix A.II).

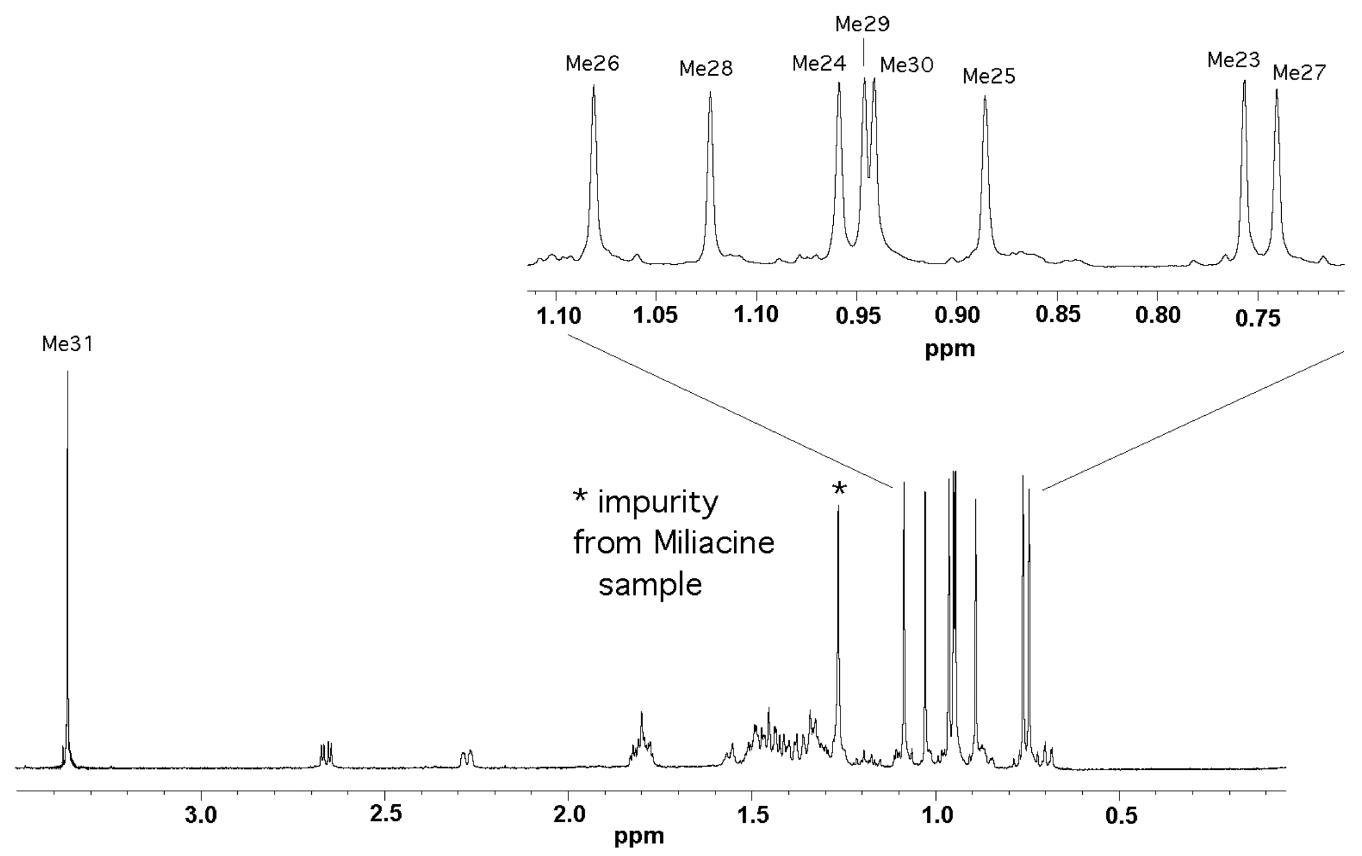

Figure 2: $600.1 \mathrm{MHz}$ proton $1 \mathrm{D}-\mathrm{NMR}$ spectrum of miliacin in $\mathrm{CDCl}_{3}(295 \mathrm{~K})$. The assignment of resonances of methyl groups is given in Table S-1, S-2 and S-3 in Appendix A.I of Supp. Info.). The peak marked by an asterisk $(\delta=1.24 \mathrm{ppm})$ is an unidentified impurity. 


\subsection{Analysis of anisotropic NAD signals of methyl groups}

Miliacin is a very illustrative example of the analytical performance of anisotropic NAD 2D-

NMR to determine the intramolecular site-specific isotope distribution. Indeed, on the isotropic NAD

1D-NMR spectrum of miliacin, the resonances of methyl groups, Me24, Me29 and Me30 as well as

Me23 and Me27 are not spectrally resolved (even at 92.1 MHz) (see Fig. S-4 in Appendix A.I of

Supp. Info.). As a consequence, only two broad ${ }^{2} \mathrm{H}$ resonances are observed, thus preventing a specific determination of their respective peak areas, and consequently the associated $(\mathrm{D} / \mathrm{H})$ ratios at each individual site.

Fig. 3a shows the shielded region of methyl groups (Me23- Me30) of the tilted $Q$-resolved Fz 2D map of miliacin recorded in PBLG/CHCl 3 at $295 \mathrm{~K}$ (see Fig. S-7, Appendix A.II of Supp. Info. for the full map). As expected, all methyl signals are now separated on the basis of their $\mathrm{d}$ their $\delta\left({ }^{2} \mathrm{H}\right)$ and $\Delta v_{\mathrm{Q}}\left({ }^{2} \mathrm{H}\right.$ ). The sixteen ${ }^{2} \mathrm{H}$ resonances (8 quadrupolar doublets) detected on the 2D map correspond to eight inequivalent methyl sites, Me23-Me30; each of them giving one integrated signal of three ${ }^{2} \mathrm{H}$ equivalent sites. As expected, almost all QDs of methylene and methine ethylene groups of miliacin do not clearly emerge from the spectral noise (baseline) and cannot be used reliably for quantitative purposes. In contrast, the doublets of all methyl groups are detected on $2 \mathrm{D}$ map with $\mathrm{S} / \mathrm{N}$ ratios varying between 8 (Me30) and 25 (Me26) whereas a value of 35 is found for the methyl of methoxy group (Me31) (Table 1). Due to the small amount of miliacin solubilized in the mesophase and its high MW, the S/N ratios are unusually low. However a reliable (acceptable) evaluation of peak areas leading to reliable $(\mathrm{D} / \mathrm{H})$ ratios is still possible.

Table 1: Spectral data associated to anisotropic NAD signals of methyl groups of miliacin at $295 \mathrm{~K}$.

\begin{tabular}{cccccc}
\hline $\begin{array}{c}\text { Methyl } \\
\text { group }\end{array}$ & Ring & $\begin{array}{c}\delta\left(^{2} \mathrm{H}\right)^{\mathrm{a}} \\
(\mathrm{ppm})\end{array}$ & $\begin{array}{c}\Delta_{1 / 2} \\
(\mathrm{~Hz})\end{array}$ & $\mathrm{S} / \mathrm{N}$ & $\begin{array}{c}\left|\Delta v_{\mathrm{Q}}\right| \\
(\mathrm{Hz})\end{array}$ \\
\hline $\mathrm{Me}_{27}$ & $\mathrm{C}$ & $0.771(0.746)$ & 2.4 & 24 & 309 \\
$\mathrm{Me}_{23}$ & $\mathrm{~A}$ & $0.774(0.763)$ & 2.8 & 22 & 36 \\
$\mathrm{Me}_{25}$ & $\mathrm{~A}$ & $0.905(0.891)$ & 3.3 & 12 & 275 \\
$\mathrm{Me}_{30}$ & $\mathrm{E}$ & $0.978(0.948)$ & 3.6 & 8 & 272 \\
$\mathrm{Me}_{29}$ & $\mathrm{E}$ & $0.999(0.952)$ & 5.6 & 9 & 152 \\
$\mathrm{Me}_{24}$ & $\mathrm{~A}$ & $0.982(0.965)$ & 3.3 & 9 & 296 \\
$\mathrm{Me}_{28}$ & $\mathrm{E}$ & $1.057(1.029)$ & 3.3 & 17 & 292 \\
$\mathrm{Me}_{26}$ & $\mathrm{C}$ & $1.105(1.086)$ & 2.3 & 25 & 314 \\
$\mathrm{Me}_{31}$ & $\mathrm{~A}$ & $3.399(3.368)$ & 2.1 & 35 & 193 \\
$\mathrm{CHCl}_{3}$ & - & $7.270(7.270)$ & 1.8 & $3000^{(6)}$ & 273 \\
\hline
\end{tabular}

(a) $\delta\left({ }^{2} \mathrm{H}\right)$ measured on the $F_{2}$ projection of anisotropic NAD 2D spectrum $\left(\delta_{\text {chloroform }}=7.27 \mathrm{ppm}\right)$. 
On the tilted 2D map, it becomes possible to extract a single or several columns (projection of columns) associated to a single or several ${ }^{2} \mathrm{H}$ site(s) (Lesot et al., 2008). Four NAD 1D sub-spectra (containing the signal associated to one to four ${ }^{2} \mathrm{H}$ sites) were selected (Fig. 4) in order to separate reliably all quadrupolar doublets (regions selected are shown in Fig. S-8 in Appendix A.II. of Supp. Info.) Table 1 lists the ${ }^{2} \mathrm{H}$ quadrupolar splittings in $\mathrm{Hz}$ (distance in $\mathrm{Hz}$ between two components of each ${ }^{2} \mathrm{H}$ doublet). As seen, the $\Delta v_{\mathrm{Q}}$ 's (in absolute value) varies from 36 to $314 \mathrm{~Hz}$, but the majority of doublets (6/9) range from 272 to $314 \mathrm{~Hz}$. As expected by using 2D NMR approach, the NAD signals associated to each methyl group of miliacin are spectrally distributed (on the 2D map) on the basis of their ${ }^{2} \mathrm{H}$ chemical shifts and quadrupolar splittings. Hence it becomes possible to evaluate the areas of each doublet by peak deconvolution. For the same molecule, these areas are proportional to the number of monodeuterated isotopomers contributing to the NAD signal (three for a methyl group) and the $(\mathrm{D} / \mathrm{H})_{1}^{\text {Me }}$ ratio at methyl site i (results, discussion in Section 4.4).

(b)

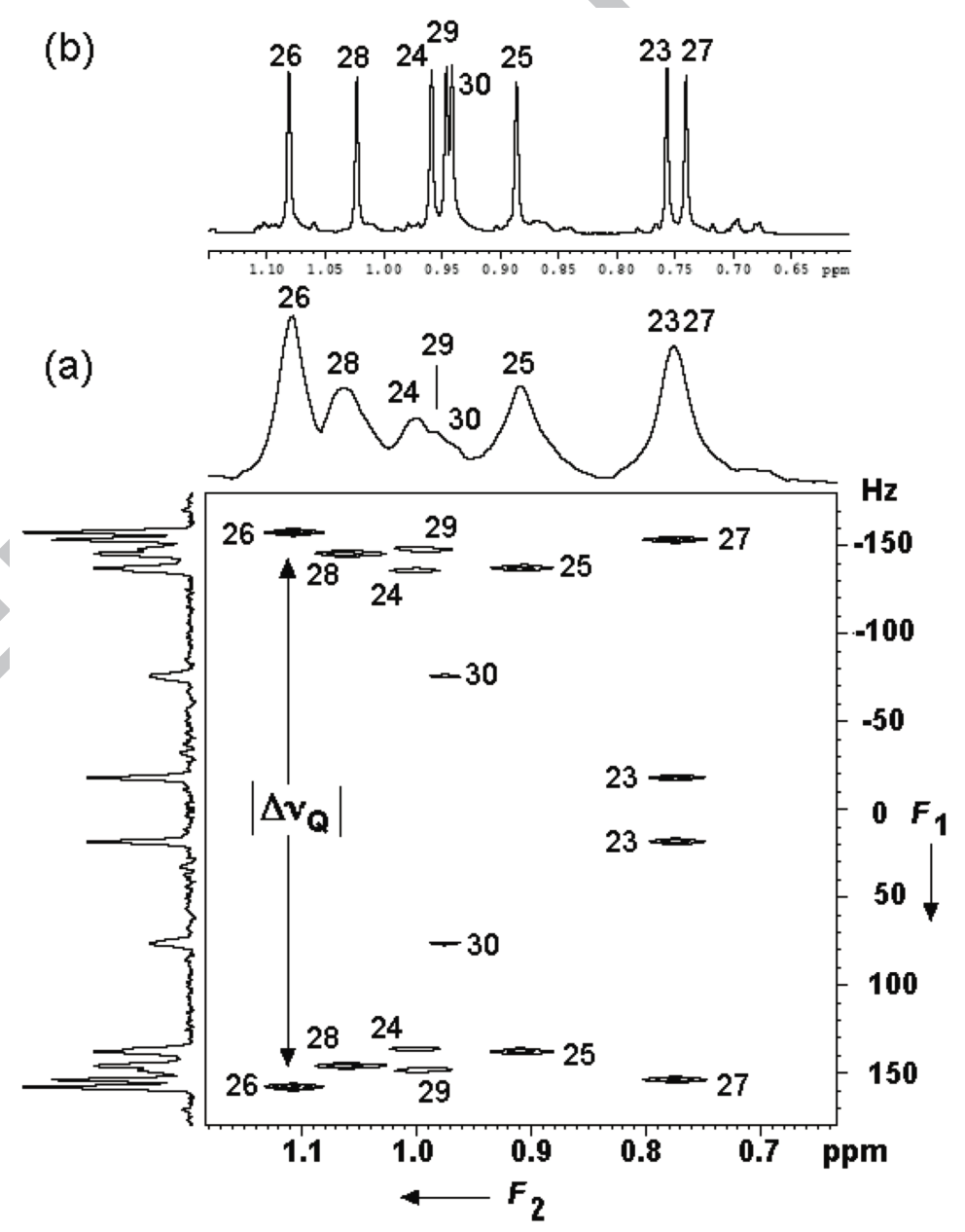

(a)

Figure 3: (a) Methyl region (Me31 not shown) of the $92.1 \mathrm{MHz}$ NAD tilted $Q$-resolved Fz 2D map of miliacin dissolved in $\mathrm{PBLG} / \mathrm{CHCl}_{3}$ and recorded at $295 \mathrm{~K}$. (b) $600 \mathrm{MHz}$ proton 1D spectrum of miliacin in $\mathrm{CHCl}_{3}$ plot at the horizontal same scale (in ppm). A lorenzian filtering $\left(\mathrm{LB}=1.5 \mathrm{~Hz}\right.$ ) has been applied in both spectral dimensions. On the $F_{1}$ and $F_{2}$ axes are shown the spectral 2D projections. Note the significant variations of peak intensity of ${ }^{2} \mathrm{H}$ doublets in $F_{1}$ dimension illustrating the enrichment/depletion in deuterons. 
As far as possible, the assignment of ${ }^{2} \mathrm{H}$ resonances in $F_{2}$ dimension on the $Q$-resolved $\mathrm{Fz}$ map of miliacin can be derived from the position of ${ }^{1} \mathrm{H}$ lines of methyl groups observed the isotropic ${ }^{1} \mathrm{H}$ spectrum (see Fig. 3). However when ambiguities exist (as for sites 23 and 27), further arguments based on the orientation of the $\mathrm{C}-\mathrm{CH}_{3}$ axis (see Fig. 5) can help to assign the quadrupolar doublets on the basis of their magnitude. Indeed as the quadrupolar splittings are proportional to the order parameter, $\mathrm{S}_{\mathrm{C}-\mathrm{D}}$, of the C-D bond (see Eq. 1), they can be related to the relative positions of associated C-D vectors in a (rigid) molecular structure (Aroulanda et al., 2001; Lesot et al., 2015). We can therefore correlate the magnitude of ${ }^{2} \mathrm{H}$ doublets to geometrical data, thus providing complementary information for their assignment. This approach was typically useful to assign the quadrupolar doublets associated to Me23 and Me27, for instance. Detailed explanations and further discussions on the assignment of doublets are given in Appendix A.III of Supp. Info.
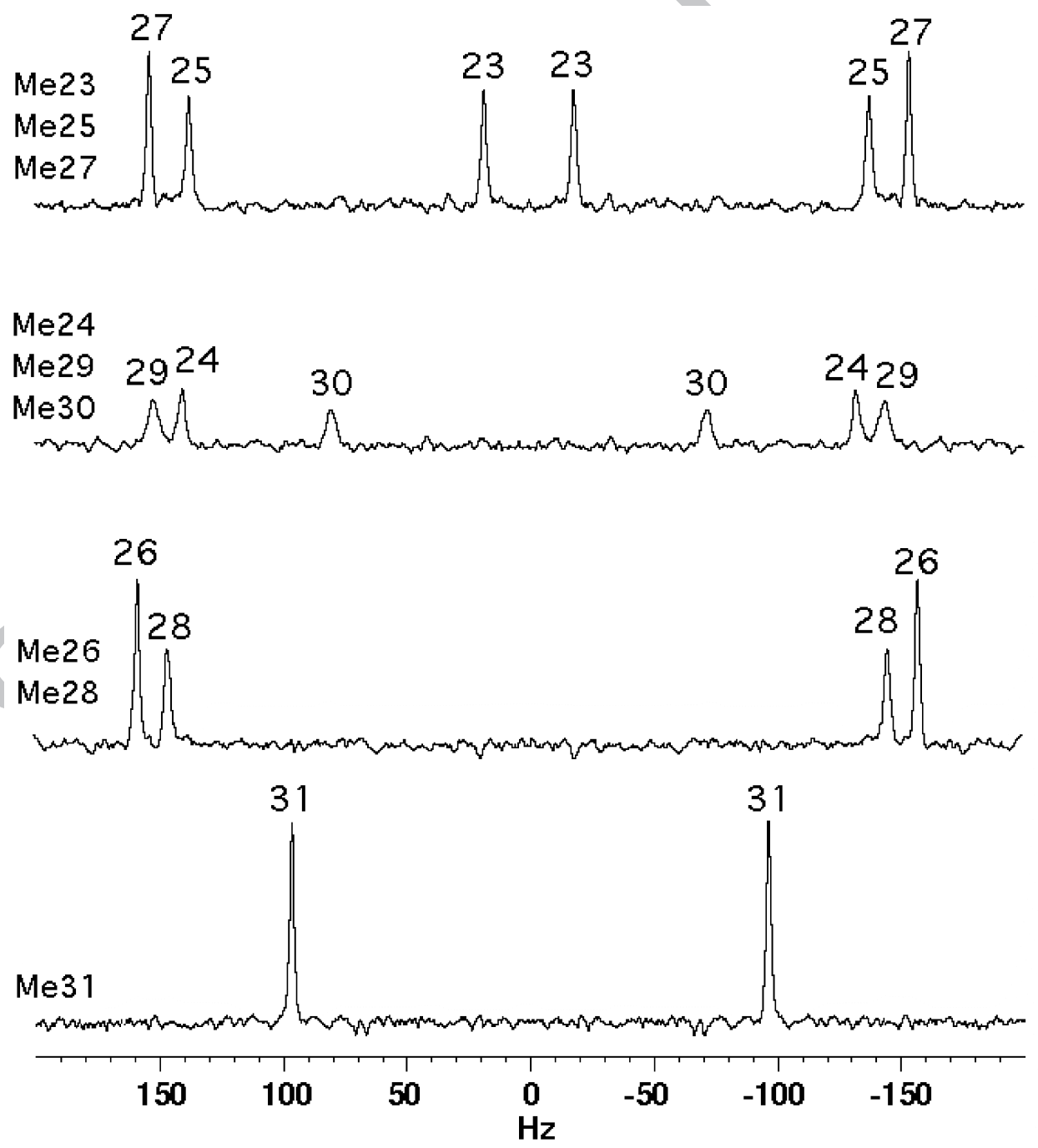

Figure 4: Series of four NAD 1D sub-spectra extracted from the tilted $Q$-resolved $\mathrm{Fz} 2 \mathrm{D}$ map showing the nine methyl groups of miliacin along with their assignments (see also Fig. S-9). Each sub-spectrum is plotted with the same amplitude of noise. Note the variation of peak intensity of ${ }^{2} \mathrm{H}$ doublets. The variations observed reveal the differences of $(\mathrm{D} / \mathrm{H})$ for each site. 


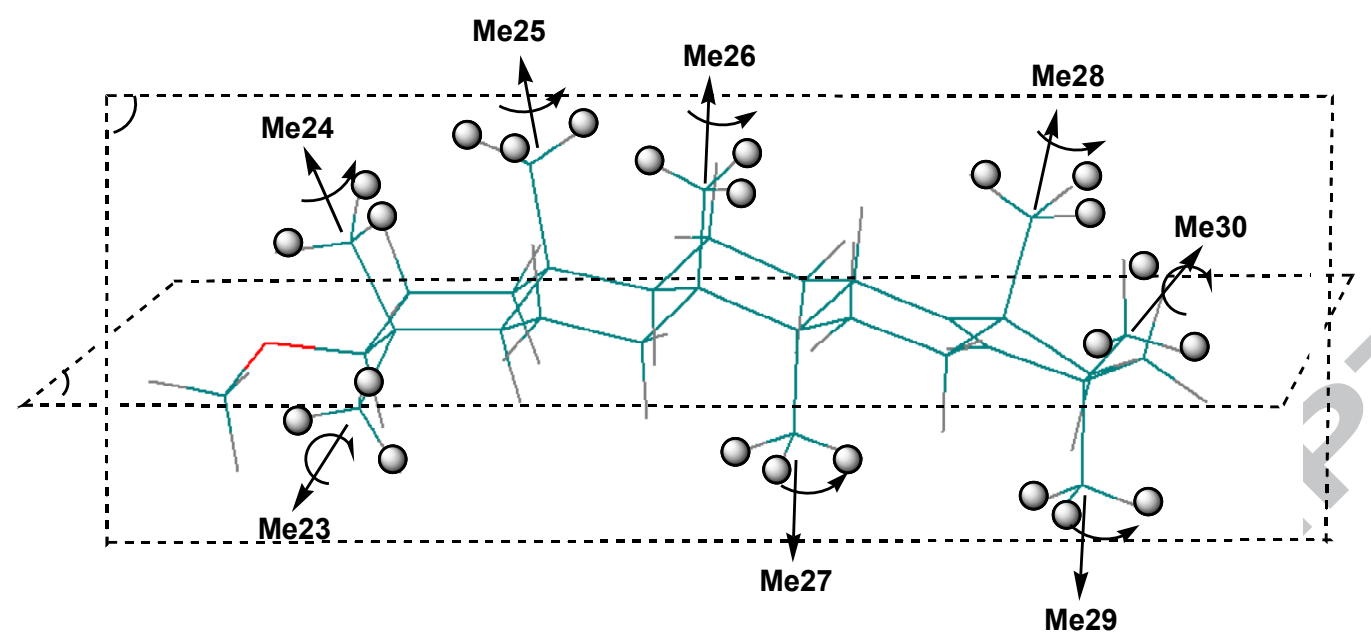

Figure 5: 3D view of the minimal energy conformation of miliacin calculated with Hyperchem 3.0 software. A semi-empirical quantum chemistry methods based on the Hartree-Fock formalism (Austin Model 1 or AM1) has been used for modeling the molecule. The minimal energy was found at $-8177.99 \mathrm{~kJ} / \mathrm{mol}$. Except for ring E distorted by the double bond, all other cycles have adopted a chair conformation. Note the difference of orientation axes of $\mathrm{C}-\mathrm{CH}_{3}$ vectors for Me23 and Me30 (close to the median horizontal molecular plan) compared to Me24 to Me29 (see also Fig. S-9 in Appendix A.II of Supp. Info.).

\subsection{Absolute $(\mathrm{D} / \mathrm{H})$ and $\delta \mathrm{D}$ values of methyl groups}

In contrast to their ${ }^{1} \mathrm{H}$ signals (Fig. 2), significant variations in the intensity of ${ }^{2} \mathrm{H}$ doublets for the nine methyl groups are observed on the 2D map or the associated $F_{1}$ and $F_{2}$ projections (Figs. 3 and 4). As NAD 2D-NMR spectra have been recorded with quantitative experimental conditions, the peak areas on projections (or peak volume on the 2D map) are in principle proportional to the number of isotopomers contributing to the NAD signal (three for a methyl group) and the isotope ratio (D/H) at each methyl site.

\subsubsection{Evaluation of relative ${ }^{2} \mathrm{H}$ peak surface by anisotropic NAD 2D-NMR}

When the direct quantification of peak surfaces on anisotropic 2D spectra (using an isotopically calibrated, internal chemical reference) is experimentally difficult as in case of miliacin (problem with mesophase, interference between the ${ }^{2} \mathrm{H}$ solute and reference signals), other strategies must be proposed. Thus the use of an electronic reference signal (ERETIC method) is a possible alternative but required special equipment not implemented in the majority of spectrometers (Akoka et al., 1999). For the study of miliacin, we have adopted a two-step protocol for quantification of relative D concentrations in methyl groups (or any other sites) consisting into: i) evaluating the relative variation of ${ }^{2} \mathrm{H}$ surfaces of each doublet using the NAD signal of methyl group of methoxy (Me31) as internal reference value; ii) determining the $(\mathrm{D} / \mathrm{H})$ and $\delta \mathrm{D}$ values of $\mathrm{Me} 31$ using either GC-irMS (see Section 4.3.2) or isotropic quantitative NAD NMR in presence of TMU (see Section 4.3.3). Note that the choice of the Me 31 as internal reference is advantageous for both methods. From GC-irMS viewpoint, the $(\mathrm{D} / \mathrm{H})_{\mathrm{Me} 31}$ ratio can be easily quantified by comparing the global $\delta \mathrm{D}$ of miliacin and the one of germanicol. From an NMR viewpoint, the isotropic ${ }^{2} \mathrm{H}$ signal of Me31 is 
isolated from other signals of miliacin, reducing errors on the measure of peak surface by deconvolution, and does not interfere with the signal of TMU.

The measurement of relative surface of peaks can be either directly performed on the 2D map or using 1D projections of selected slices extracted from the map (Massou et al., 2007; Lesot et al., 2008). Adopting this second approach, the evaluation of relative surface of doublet of methyl groups was performed as following: i) selection of 10 columns centered on the NAD signal of each inequivalent ${ }^{2} \mathrm{H}$ site and calculation of their respective $F_{1}$ projection, ii) addition of NAD signal of Me31 (10 columns) to each NAD 1D sub-spectrum; iii) determination (by signal deconvolution) of the peak surface for each methyl group, iv) calculation of the average value obtained for the six different NAD 2D spectra recorded with the same experimental conditions (acquisition and processing), assuming a reference value for the Me31 signal. In order to determine the reliability of this approach, we have compared the peak area of Me31 for the six experiments. The variation between each experiment is below $2 \%$. In column 3 of Table 2 are listed the averaged surfaces measured for the six NMR experiments, when the value for the Me31 is arbitrary set at 100 . Values for each experiment are given in Table S-4 and plotted in Fig. S-10 whereas Fig. S-11 in Appendix A.II of Supp. Info. displays the associated average values together with the SD.

\subsection{2. $\delta D_{M e 31}$ determined by $G C$-irMS and $S N I F-N M R^{\mathrm{TM}}$}

$\delta D_{\text {Me31 }}$ was first estimated by comparing the GC-irMS $\delta D$ values of miliacin $\left(\delta D_{\text {miliacin }}\right)$ and of germanicol $\left(\delta \mathrm{D}_{\text {germanicol }}\right)$ extracted from millet oil according to the following rationale and equations. We assumed no other hydrogen isotopic difference between miliacin and germanicol (see Fig. 1) than the addition of three hydrogen atoms from the Me31.

Experimentally, we obtained $\delta D_{\text {miliacin }}=-100 \pm 5 \%$ and $\delta D_{\text {germanicolacetate }}=-110 \pm 5 \%$, which gives $\delta D_{\text {germanicol }}=-108.6 \pm 5 \%$, after mathematically removing the contribution from acetic anhydride $\left(\delta D_{\text {acanh }}=-133 \pm 2 \%\right)$ according to Eq. 4:

$$
\delta \mathrm{D}_{\text {germanicol }}=\left(\frac{52 \times \delta \mathrm{D}_{\text {germanicolacetate }}-3 \times \delta \mathrm{D}_{\text {acanh }}}{49}\right) \text {. }
$$

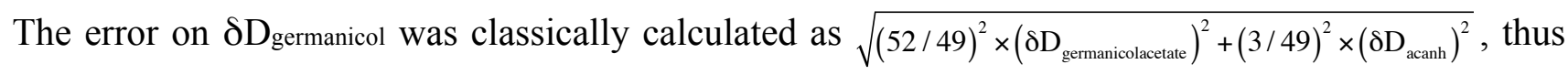
taking into account the multiplicative factors of Eq. $\mathbf{4}$ and assuming that the correlative term is null (independent variables). Note here that this $\delta \mathrm{D}_{\text {germanicol }}$ value does not take into account the $\mathrm{H}$ atom of the alcohol function that is highly exchangeable and was lost during acetylation. Hence, when calculating $\delta D_{\mathrm{Me} 31}$ in mass balance equations Eq. 4 and Eq. 5, we consider $49 \mathrm{H}$ atoms in germanicol (instead of 50) and $52 \mathrm{H}$ atoms in miliacin. 


$$
\delta D_{\text {Me31 }}=\left(\frac{52 \times \delta D_{\text {miliacin }}-49 \times \delta D_{\text {germanicol }}}{3}\right)
$$

478

The calculation in Eq. 5 gives $\delta D_{M e 31}$ equal to $+41 \%$ \% $\pm 119 \%$. Propagation of uncertainties on the $\delta D_{\mathrm{Me} 31}$ was calculated as for Eq. 4 (see Table 2, footnote i). Using Eq. 2, this corresponds to a $(\mathrm{D} / \mathrm{H})_{\mathrm{Mes} 1 \mathrm{C}}^{\mathrm{GC}-\mathrm{ims}}$ value of $162 \pm 19 \mathrm{ppm}$. Details for the conversion from $\delta \mathrm{D}$ to $(\mathrm{D} / \mathrm{H})$ are given in footnote $\mathrm{g}$ of Table 2.

A possible experimental alternative to $\mathrm{GC}$-irMS consists to determine $\delta \mathrm{D}_{\mathrm{Me} 31}$ value applying the so-called SNIF-NMR ${ }^{\mathrm{TM}}$ protocol using NAD NMR in isotropic solvent in presence of calibrated TMU (see Section 3.7). The analysis of experiments recorded indicates that standard deviation on the area ratio $\left(\mathrm{R}=\mathrm{A}_{\text {Ме31 }} / \mathrm{A}_{\text {TMU }}\right)$ was found to be equal to 0.28 (e.g. $\left.\mathrm{R}=25.2 \pm 0.6\right)$, thus indicating a very good repeatability of isotropic NAD 1D NMR experiments (see Table S-5). Knowing the (D/H) and the masses of TMU and miliacin (purity of 98\%) used, the $(\mathrm{D} / \mathrm{H})_{\mathrm{Me} 31}$ was obtained using Eq. 3; the average value was found to be equal to $154 \mathrm{ppm}$. The uncertainty value on $(\mathrm{D} / \mathrm{H})_{\mathrm{Me} 31}$ was classically calculated as $\Delta \mathrm{X}=\mathrm{X} \times \sqrt{\sum_{\mathrm{i}}\left(\Delta \mathrm{g}_{\mathrm{i}} / \mathrm{g}_{\mathrm{i}}\right)^{2}}$ where $\mathrm{g}_{\mathrm{i}}$ are the key variables of Eq. 3 (see Table 2 and S-5) and found to be equal to $\pm 10 \mathrm{ppm}$. Expressed in $\delta \mathrm{D}_{\mathrm{Me} 31}$ (from the Eq. 2), the value is equal to $-11 \pm 64 \%$ o (see Table 2, footnote e).

Conclusively, it is worthwhile noting that, although they were determined by two very distinct analytical methods, the $(\mathrm{D} / \mathrm{H})_{\mathrm{Me} 31} /\left(\delta \mathrm{D}_{\mathrm{Me} 31}\right)$ values are consistent within the uncertainty range $(162 \pm$ 19 ppm versus $154 \pm 10 \mathrm{ppm}(+41 \pm 119 \%$ versus $-11 \pm 64 \%)$. The difference on the nominal $(\mathrm{D} / \mathrm{H})_{\mathrm{Me} 31}$ value (relative discrepancy of $5 \%$ ) could be explained by the lower sensitivity of NAD NMR spectroscopy (compared to GC-irMS) in particular when samples cannot be enough concentrated in analyte.

\subsubsection{Absolute $(\mathrm{D} / \mathrm{H})$ and $\delta \mathrm{D}$ values of methyl groups 23 to 30}

From $(\mathrm{D} / \mathrm{H})_{\mathrm{Me} 31}$ value determined by the SNIF-NMR ${ }^{\mathrm{TM}}$ protocol or GC-irMS, it becomes possible to evaluate the $(\mathrm{D} / \mathrm{H})$ value for each methyl group $(\mathrm{D} / \mathrm{H})_{\mathrm{Mei}}$ and corresponding $\delta \mathrm{D}_{\mathrm{Mei}}$ with $\mathrm{i}=$ 23 to 30$)$ in miliacin, using relative $(\mathrm{D} / \mathrm{H})$ values previously determined using the anisotropic NAD NMR experiment (Section 4.3.1). All data and details of the calculation are given in Table 2 and footnotes. A graphical comparison of the $(\mathrm{D} / \mathrm{H})_{\mathrm{Mei}}$ and $\delta \mathrm{D}_{\mathrm{Mei}}$ variations versus the methyl groups is proposed in Figs 6a and $\mathbf{6 b}$. Large variations of $(\mathrm{D} / \mathrm{H})_{\text {Mei }}$ values (up to a factor $\approx 2$ ) exist from one site to another one. Except for Me31, the $(\mathrm{D} / \mathrm{H})_{\text {Mei }}$ values are significantly below the V-SMOW value. This deuterium depletion in lipids produced by autotrophs is expected from biosynthetic fractionation (Sessions et al., 1999). Besides for Me31, Me26 and Me27 appear to be the less depleted methyl 
511 Table 2: Values of $(\mathrm{D} / \mathrm{H})_{\mathrm{Mei}}($ in $\mathrm{ppm})$ and $\delta \mathrm{D}_{\mathrm{Mei}}($ in $\%$ ) of the methyl groups of miliacin.

\begin{tabular}{|c|c|c|c|c|c|c|}
\hline \multirow[b]{2}{*}{ Ring } & \multirow[b]{2}{*}{$\begin{array}{l}\text { Methyl }^{a} \\
\text { group }\end{array}$} & \multirow[b]{2}{*}{ Peak areab } & \multicolumn{2}{|c|}{ Anisotropic NMR / SNIF-NMR ${ }^{\mathrm{TM}}$} & \multicolumn{2}{|c|}{ Anisotropic NMR / GC-irMS } \\
\hline & & & $\begin{array}{c}(\mathrm{D} / \mathrm{H})_{\mathrm{Me}_{\mathrm{i}}}{ }^{\mathrm{p}} \\
\mathrm{ppm}\end{array}$ & $\begin{array}{c}\delta D_{\text {Mei }}{ }^{e} \\
\% \circ\end{array}$ & $\begin{array}{l}(\mathrm{D} / \mathrm{H})_{\mathrm{Me}_{\mathrm{i}}}{ }^{\mathrm{f}} \\
\mathrm{ppm}\end{array}$ & $\begin{array}{c}\delta D_{M e i}{ }^{h} \\
\% o\end{array}$ \\
\hline A & $M e_{31}$ & $100(0.0)$ & $154 \pm 10^{d}$ & $-11 \pm 64$ & $162 \pm 19^{g}$ & $+41 \pm 119^{i}$ \\
\hline \multirow{3}{*}{ A } & $\mathrm{Me}_{23}$ & $74.1 \pm 13.8(6.9)$ & $114 \pm 23$ & $-268 \pm 148$ & $120 \pm 25$ & $29 \pm 162$ \\
\hline & $\mathrm{Me}_{24}$ & $54.6 \pm 17.6(8.8)$ & $84 \pm 28$ & $-461 \pm 180$ & $88 \pm 30$ & $-432 \pm 193$ \\
\hline & $\mathrm{Me}_{25}$ & $73.5 \pm 14.8(7.4)$ & $113 \pm 24$ & $-274 \pm 154$ & $119 \pm 28$ & $-235 \pm 177$ \\
\hline \multirow{2}{*}{ C } & $\mathrm{Me}_{26}$ & $90.3 \pm 10.2(5.1)$ & $139 \pm 18$ & $-107 \pm 122$ & $146 \pm 23$ & $-60 \pm 151$ \\
\hline & $\mathrm{Me}_{27}$ & $82.4 \pm 9.6(4.8)$ & $127 \pm 17$ & $-186 \pm 116$ & $133 \pm 22$ & $-143 \pm 139$ \\
\hline \multirow{3}{*}{$E$} & $\mathrm{Me}_{28}$ & $76.8 \pm 14.2(7.1)$ & $118 \pm 23$ & $-242 \pm 154$ & $124 \pm 27$ & $-201 \pm 173$ \\
\hline & $\mathrm{Me}_{29}$ & $66.8 \pm 12.0(6.0)$ & $103 \pm 20$ & $-340 \pm 128$ & $108 \pm 23$ & $-305 \pm 148$ \\
\hline & $\mathrm{Me}_{30}$ & $41.5 \pm 10.4(5.4)$ & $64 \pm 17$ & $-590 \pm 109$ & $67 \pm 18$ & $-568 \pm 116$ \\
\hline
\end{tabular}

a) The methyl group Me31 is used as internal reference.

b) Average value of peak areas of NAD signals of methyl groups measured on anisotropic NAD 2D spectra (six NMR experiments) when the methoxy group is arbitrary calibrated at 100 . In parenthesis is given the value of the simple standard deviation $\left(\sigma_{n}\right)$ on peak areas calculated as: $\sigma_{n}=\sqrt{\frac{1}{n} \sum_{i=1}^{n}\left(x_{i}-\bar{x}\right)^{2}}$ where $n=6$. The uncertainty, noted $\Delta X$, on value $X($ such

as $\mathrm{X}=\mathrm{x} \pm \Delta \mathrm{X}$ ) is calculated (in ppm) as $\Delta \mathrm{X}=\mathrm{k} \times \sigma_{\mathrm{n}}$ where $\mathrm{k}=2$, namely leading to a confidence interval of $95 \%$ [x $1.96 \sigma ; \mathrm{x}+1.96 \sigma]$.

c) The $(\mathrm{D} / \mathrm{H})_{\mathrm{Me} 23-\mathrm{Me} 30}$ values in ppm (methyl groups 23 to 30$)$ are calculated as $(\mathrm{D} / \mathrm{H})_{\mathrm{Me} 23-\mathrm{Me} 30}=\left(\% \mathrm{~A}_{\mathrm{Me} 23-\mathrm{M} 30 \mathrm{O}}^{\text {Aniso }}\right) \times(\mathrm{D} / \mathrm{H})_{\mathrm{Me} 31}^{\mathrm{SNF}-\mathrm{NMR}}$, where $(\mathrm{D} / \mathrm{H})_{\mathrm{Me} 31}^{\mathrm{NADNR}}$ is determined by isotropic NAD $1 \mathrm{D}-\mathrm{NMR}$ (i.e. $(\mathrm{D} / \mathrm{H})_{\mathrm{Me} 31}^{\mathrm{SNIF}-\mathrm{MMR}}=154 \pm 10 \mathrm{ppm}$, see Table S-4). The

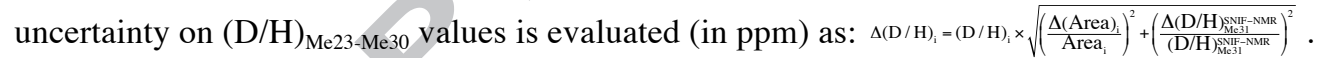

d) The ${ }^{(\mathrm{D} / \mathrm{H})_{\text {Me } 31}^{\text {SNIF }}}$ value in \%o (methyl group 31$)$ is experimentally determined by SNIF-NMR ${ }^{\mathrm{TM}}$ protocol in isotropic solvent. See Table S-5 for the calculation of uncertainty on $(\mathrm{D} / \mathrm{H})_{\mathrm{Me} 31}^{\mathrm{NADN}}$.

e) The $\delta D_{M e 23-M e 31}$ values in \%o are calculated using Eq. 2. Considering that the $(\mathrm{D} / \mathrm{H})_{\mathrm{V}-\mathrm{Smow}}$ value is a constant

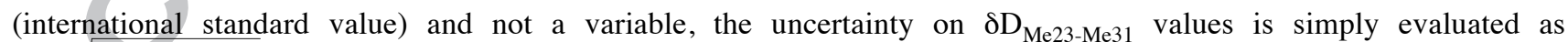
$\Delta \delta_{\mathrm{Mei}}=\sqrt{\left(1000 \times \frac{\Delta(\mathrm{D} / \mathrm{H})_{\mathrm{Mei}}}{(\mathrm{D} / \mathrm{H})_{\mathrm{V}-\mathrm{swow}}}\right)^{2}}$, assuming that correlation term is null.

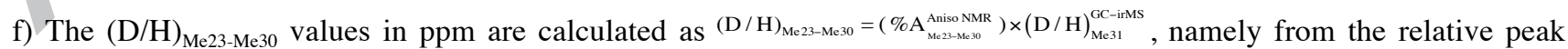
surfaces $(\%)$ measured on anisotropic NMR spectra (see Table S-4) and using the $(\mathrm{D} / \mathrm{H})_{\text {Me31 }}^{\mathrm{GC} \text { irMS }}$ value (ppm) as reference.

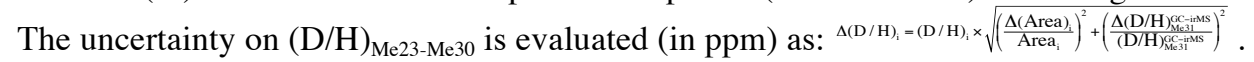

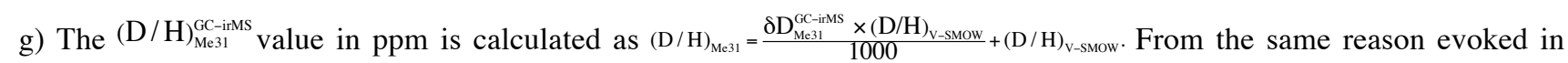
footnote e, the uncertainty on $(\mathrm{D} / \mathrm{H})_{\mathrm{Me} 31}^{\mathrm{GC}-\mathrm{irMS}}$ is evaluated as $\Delta(\mathrm{D} / \mathrm{H})_{\mathrm{Mei}}=\sqrt{\left(\frac{(\mathrm{D} / \mathrm{H})_{\mathrm{V}-\mathrm{SMOW}} \times \Delta \delta_{\mathrm{Mei}}}{1000}\right)^{2}}$, leading to a value of $\pm 19 \mathrm{ppm}$. 


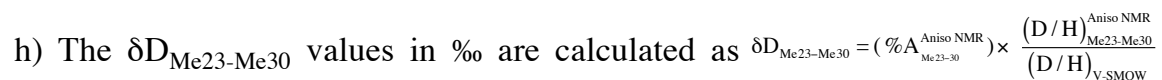

. Note that these values cannot

(a)

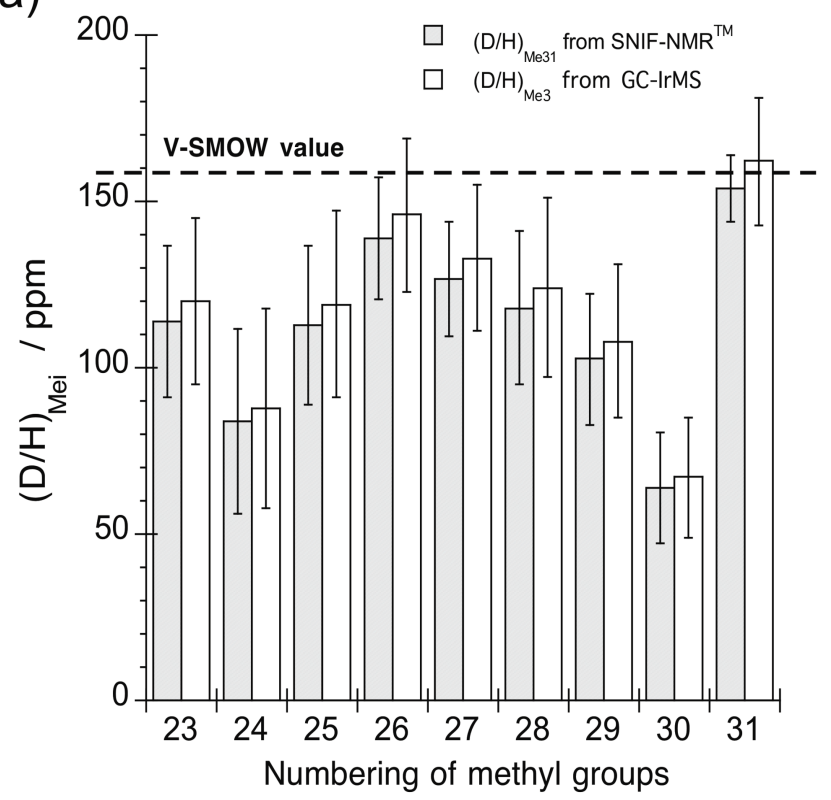
$\mathrm{Me} 30$ and Me24 are strongly depleted $\left(\delta \mathrm{D}_{\mathrm{Mei}} \sim-500 \%\right)$. Figure S-12)." (b)

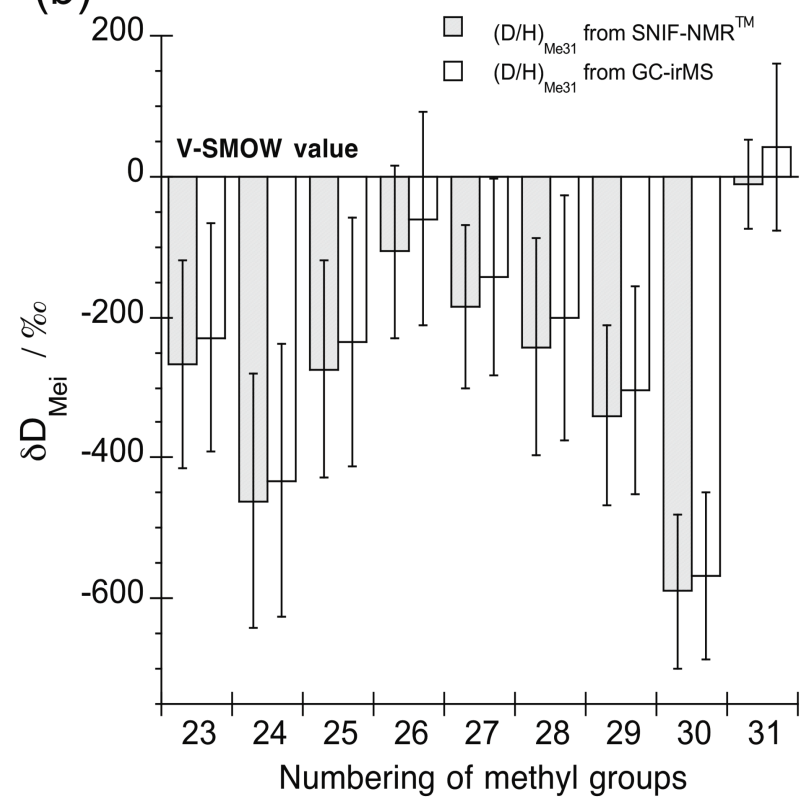

directly be obtained from $\% \mathrm{~A}_{\mathrm{Me} 23-30}^{\mathrm{Aniso} N \mathrm{NR}}$ and $\delta \mathrm{D}_{\mathrm{Me} 31}^{\mathrm{GC}-\mathrm{rrMS}}$ values due to the non-linearity of Eq. 2 . For the same reason evoked in footnote e, the uncertainty on $\delta \mathrm{D}_{\mathrm{Mei}}$ is -simply evaluated as $\Delta \delta_{\mathrm{Mei}}=1000 \times \frac{\Delta(\mathrm{D} / \mathrm{H})_{\mathrm{Mci}}}{(\mathrm{D} / \mathrm{H})_{\mathrm{V}-\mathrm{s} \text { Now }}}$.

i) The $\delta D_{\mathrm{Me} 31}^{\mathrm{GC} 1 \mathrm{irMS}}$ value in \%o was experimentally determined by GC-irMS. The calculation of uncertainty on $\delta \mathrm{D}_{\mathrm{Me} 31}^{\mathrm{GC}-\text { irMS }}$ is evaluated as $\Delta \delta \mathrm{D}_{\mathrm{Me} 31}^{\mathrm{GC}-\mathrm{rrMS}}=\sqrt{(52 / 3)^{2} \times\left(\delta \mathrm{D}_{\text {germanicolacetate }}\right)^{2}+(49 / 3)^{2} \times\left(\delta \mathrm{D}_{\text {acanh }}\right)^{2}}$ and gives $\pm 119 \%$ (see main text).

groups $\left(\delta \mathrm{D}_{\mathrm{Mei}} \sim-100 \%\right.$ ), followed by Me23, Me25, Me28 and Me29 ( $\delta \mathrm{D}_{\text {Mei }} \sim-250 \%$ ), whereas

More interesting is actually the global variation of $(\mathrm{D} / \mathrm{H})_{\mathrm{Me} 23-\mathrm{Me} 30}$ values (the exogeneous methyl 31 group is disregarded), that can be modeled as a quasi symmetrical, bell curve, the biosynthetic implication of which is discussed below. Note also that these conclusions may still hold based on the relative variation of peak areas measured on anisotropic NAD 2D map of miliacin (see Table S-4 and

Figure 6: Variation of (a) $(\mathrm{D} / \mathrm{H})$ ratios in $\mathrm{ppm}$ and (b) $\delta \mathrm{D}$ in \%o for each methyl group of miliacin when $(\mathrm{D} / \mathrm{H})_{\mathrm{Me} 31}$ is evaluated by the SNIF-NMR ${ }^{\mathrm{TM}}(154 \pm 10 \mathrm{ppm}$ or $-11 \pm 64 \%$ o $)$ and by GCirMS $(162 \pm 19 \mathrm{ppm}$ or $41 \pm 119 \%$ ). Excluding the exogenous methyl group 31, note the (inverted) quasi-symmetrical bell shape of both plots.

\section{DISCUSSION}

\subsection{Implications for biosynthesis}

The heterogeneous distribution of $\delta \mathrm{D}_{\text {Mei }}$ values in miliacin can be explained by the different steps involved in the biosynthesis of this molecule, by tracking back the origin of methyl groups (Fig. 
7). As for any C-3 oxygenated pentacyclic triterpenes in other vascular plants, miliacin is produced in the cytosol from mevalonic acid, through the mevalonate pathway (i.e. Sachse et al., 2012). Mevalonic acid is converted into isopentenyl pyrophosphate that can be isomerized into dimethylallyl pyrophosphate. Then, farnesyl pyrophosphate is synthesized by the addition of two isopentenyl pyrophosphate units and a dimethylallyl pyrophosphate unit. Oxidosqualene is synthesized by the tail-to-tail combination of two farnesyl pyrophosphate units and is then cyclized by an oxidosqualene cyclase.
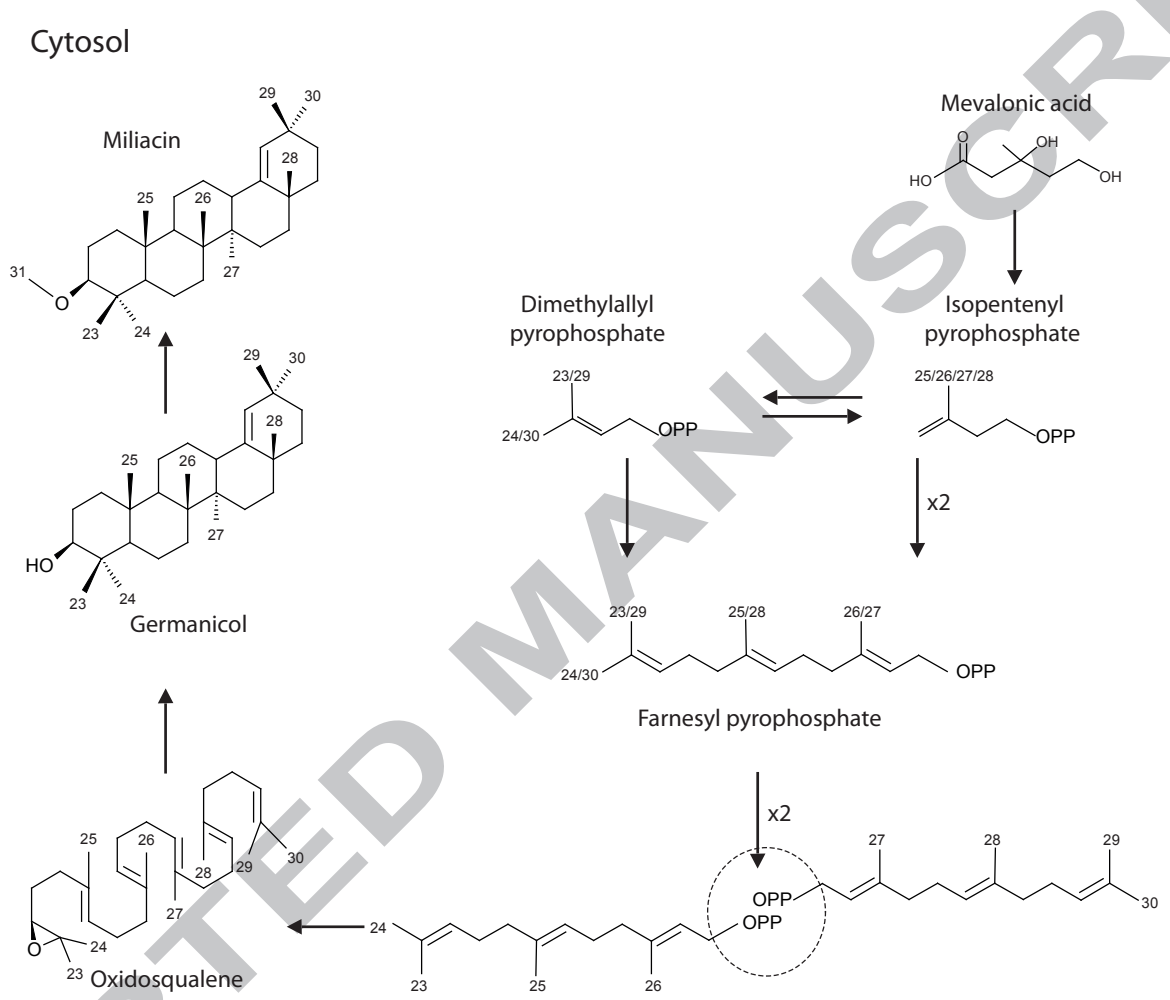

Figure 7: Synthetic pathway of miliacin in the cytosol. Modified from Sachse et al. (2012).

Hence, from a biosynthetic point of view, Me24-Me30, Me23-Me29, Me25-Me28 and Me26-Me27 are isotopically equivalent because they derive from the same methyl groups in the farnesyl pyrophosphate unit. This biosynthetic equivalence explains reasonably the symmetry and the "bellcurve" variation of $(\mathrm{D} / \mathrm{H})_{\mathrm{Mei}} /\left(\delta \mathrm{D}_{\mathrm{Mei}}\right)$ values of Me23 to Me30 as observed in Fig. 6. Farnesyl pyrophosphate is produced by head-to-tail combination of two isopentenyl pyrophosphate units and a dimethylallyl unit. Thus, Me25, Me26, Me27 and Me28 in miliacin originate from the same methyl groups in isopentenyl pyrophosphate, whereas Me23, Me29, Me24 and Me30 originate from the dimethylallyl pyrophosphate. The dimethylallyl pyrophosphate itself results from the isomerization of isopentenyl pyrophosphate by an isopentenyl diphosphate isomerase (Sachse et al., 2012).

During this process, the formation of a carbocation affects hydrogen atoms of Me24/Me30. This could explain their D depletion when compared to other methyl groups. As already noted, Me31 is highly enriched when compared to other methyl groups. We have currently no information on the 
origin of this methyl group that would explain such a relative D enrichment. These results for miliacin can be directly extrapolated to any compound with an oleanane, and potentially an ursane or lupane structure. For compounds that originate from oleanane after successive migrations of methyl groups (friedo rearrangements leading to structures such as taraxerane, glutinane, multiflorane and friedelane; i.e Xu et al., 2004), additional fractionations of hydrogen can be expected.

583

584

585

\subsection{Implications for diagenesis}

Diagenesis of vascular plant C-3 oxygenated pentacyclic triterpenes can potentially consist of several structural modifications that comprise loss of functional groups, ring-A degradation, epimerisations, double bond migrations, loss or migration of methyl groups (Rullkötter et al., 1994) and aromatization (i.e. Fig. 8 and Wolff et al., 1989). No discernible difference in $\delta^{13} \mathrm{C}$ values has been found during aromatization between biochemical precursors and diagenetic byproducts (Freeman et al., 1994). Preliminary results in organic archaeological layers showed significant D depletion of diagenetic derivatives compared to their potential biochemical precursors whereas no carbon isotopic shift was recorded (Jacob et al., 2011).
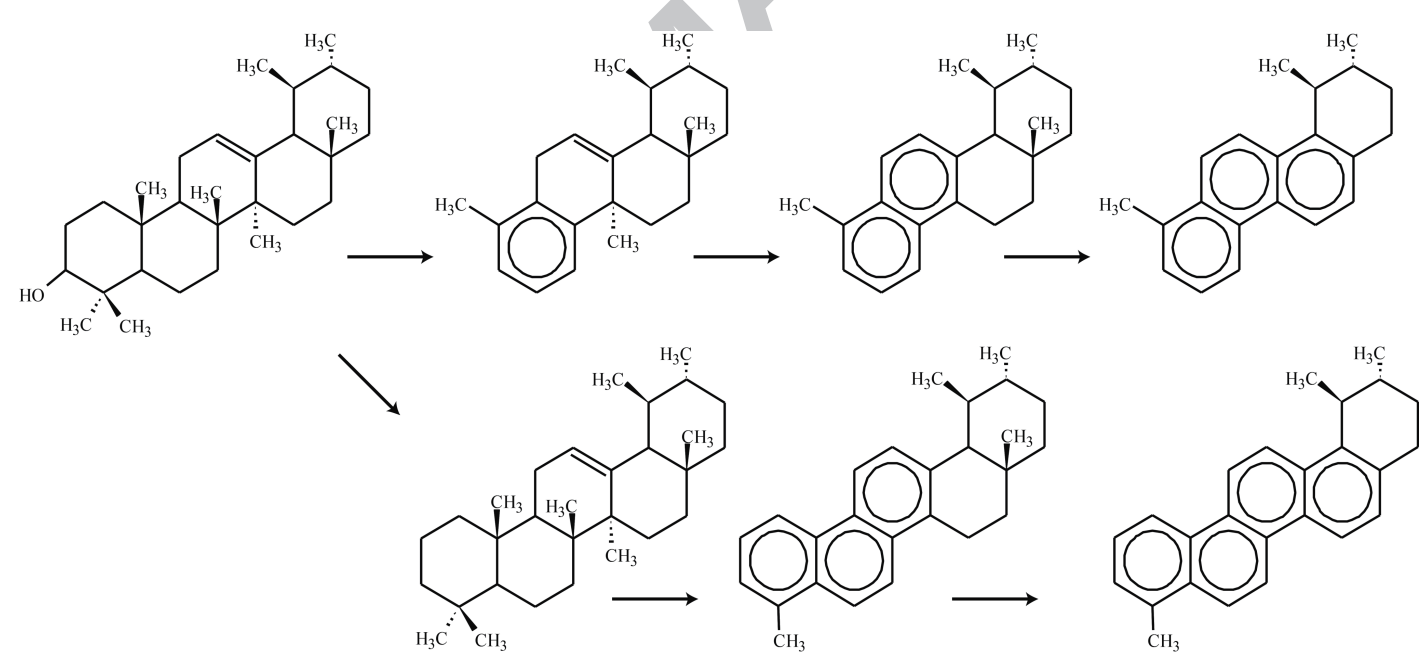

Figure 8: Potential diagenetic pathways of pentacyclic triterpenes (here starting from $\alpha$-amyrin) illustrating the loss of hydrogen atoms related to methyl groups, methylene/methine. Modified from Wolff et al. (1989).

Our results have shown significant variations in $\delta \mathrm{D}_{\text {Mei }}$ values of methyl groups in miliacin with a range $>500 \%$. Thus, removing of methyl groups during diagenesis could significantly enrich diagenetic by-products compared to their biochemical precursor. But, as depicted in Fig. 8, the loss of methyl groups during diagenesis is always associated with the loss of hydrogen atoms in methylene and methine groups associated to rings. Thus, in order to fully understand any isotopic shift during diagenesis, it is necessary to take into account $\delta \mathrm{D}$ values of methylene and methine $\left(\delta \mathrm{D}_{\text {meth }}\right)$. Miliacin is composed by 52 hydrogen atoms of which 25 are in methine or methylene groups and $3 * 9=27$ compose methyl groups. The average $\delta \mathrm{D}_{\text {meth }}$ value can thus be accessed by mass 
balance according to equation Eq. 5 .

608

609

610

611

612

613

614

615

616

617

618

619

620

621

622

623

624

625

626

627

628

629

630

631

632

633

634

635

636

637

638

639

640

641

$$
\delta \mathrm{D}_{\text {Meth }}=\left(\frac{52 \times \delta \mathrm{D}_{\text {miliacin }}-3 \times \sum \delta \mathrm{D}_{\text {Mei }}}{25}\right)
$$

Using $\delta D_{\text {Mei }}$ values of methyl groups from anisotropic NMR / SNIF-NMR ${ }^{\mathrm{TM}}$ combined approach (Table 2, column 5) and the $\delta D_{\text {miliacin }}=-100 \%$ in Eq. 6, we obtain an average $\delta D_{\text {meth }}=$ $89 \%$. Using $\delta D_{\text {Mei }}$ values of methyl groups from GC-irMS, we obtain $\delta D_{\text {meth }}=48 \%$. From these results it appears that methylene and methine are, on average, largely enriched in D compared to methyl groups. One could thus expect that, during diagenesis, any D-enrichment of the diagenetic byproduct compared to its precursor due to the loss of depleted methyl groups could be counterbalanced by D-depletion due to the associated loss of D-enriched methylene and methine. Nevertheless, in the absence of information on the heterogeneous distribution of $\mathrm{D}$ in methylene and methine, it is yet impossible to fully forecast the impacts of pentacyclic triterpenes degradation on the hydrogen isotopic composition of their by-products. In addition, only removal of hydrogen atoms is here considered but fractionation processes can be expected from the preferential biotic or abiotic degradation of biochemical precursors.

\section{CONCLUSION}

Obtaining the site-specific $\mathrm{H}$ isotope distribution in biomarkers by a reliable method is crucial but has been analytically challenging. GC-irMS allows $\delta D$ values determination at a molecular scale but does not inform on any preferential position of $\mathrm{H}$ isotopes on molecular sites. In contrast, anisotropic NAD 2D-NMR spectroscopy provides more detailed information on isotope location within molecules. This study explains how and why NAD 2D-NMR using weakly aligning LC is a fruitful analytical tool able to overcome difficulties associated to isotropic NAD 1D-NMR (SNIFNMR), with the final aim of studying the site-specific distribution of hydrogen isotopes. By coupling anisotropic and isotropic NAD NMR techniques or anisotropic NAD NMR and GC-irMS measurements, we were, for the first time, able not only to establish the relative distribution of hydrogen isotopes in methyl groups of miliacin, but also to afford quantitative $(D / H)$ and $\delta D$ values for each methyl group.

The resulting distribution of $(\mathrm{D} / \mathrm{H})$ values of methyl groups in miliacin provides detailed information that is consistent with its biosynthetic pathways; i.e. miliacin results from the addition of a methyl group on germanicol that is synthesized through the cyclisation of oxidosqualene. This later is produced by the condensation of two farnesyl pyrophosphate units, themselves built from two isopentenyl pyrophosphate units and a dimethylallyl pyrophosphate unit. The heterogeneous distribution of site-specific $\delta \mathrm{D}$ values revealed in this study could have major consequences on the 
$\delta \mathrm{D}$ values of diagenetic derivatives of pentacyclic triterpenes since removal of methyl groups is often observed in diagenetic pathways. Although this work paves the way to exciting prospects in the frame of a better understanding of hydrogen isotopic changes during pentacyclic triterpene diagenesis, thus improving any climate reconstruction based on these derivatives, the next challenge will consist of experimentally evaluating the $\delta \mathrm{D}$ values of all hydrogen sites in biomarkers in order to have a complete picture of their heterogeneous distribution. By achieving this task, we expect being able to forecast $\delta \mathrm{D}$ values of diagenetic derivatives from their precursors or to calculate the $\delta \mathrm{D}$ values of biochemical precursors through $\delta \mathrm{D}$ values of their diagenetic derivatives.

Various analytical difficulties (assignment of the anisotropic NAD signals, low $\mathrm{S} / \mathrm{N}$ ratios, ...) met and discussed in this study are both related to the structure and the low solubility of miliacin. They are therefore highly specific to this structurally-complex geological biomarker, and will not necessarily come up gain when other (simpler) organosoluble biomakers will be studied. As seen here, possible protocols/strategies/solutions were proposed to overcome them, thus showing that NAD 2D-NMR in LC remains an adaptable method able to face the majority of problems associated to given analyte. In all cases, the possibility to significantly increase the concentration of deuteroisotopomers in NMR samples and/or record the NAD experiments by using very high-field NMR spectrometers $\left(\mathrm{B}_{\mathrm{o}}>14 \mathrm{~T}\right)$ still equipped by $\mathrm{a}^{2} \mathrm{H}$ cryoprobe are the most direct way to overcome the sensitivity problem, rendering the accuracy of measurements higher.

\section{ACKNOWLEDGMENTS}

French authors thank CNRS and University of Paris-Sud for their continuous financial support. P.L. thanks also Dr. Isabelle Billault for the gift of calibrated TMU and J.-P. Baltaze for his help. J.J. is grateful to R. Boscardin for her technical support and I. Lamour (HITEX, Vannes, France) for providing millet oil. This work is also a part of the ANR Project PalHydroMil project, supported by Agence Nationale de la Recherche grant (ANR JCJC, 2011-2013). V.T. was supported by PalHydroMil and Le STUDIUM Loire Valley Institute for Advanced Studies for her participation in this study. The authors wish to thank Pr. John Hayes and the two anonymous reviewers for their constructive comments on an earlier version of the manuscript.

\section{REFERENCES}

van Aarssen B.G.K., Alexander R. and Kagi R.I. (2000) Higher plant biomarkers reflect palaeovegetation changes during Jurassic times. Geochim. et Cosmochim. Acta 64, 14171424.

Akoka. S., Barantin L., Trierweiler M. (1999) Concentration measurement by proton NMR using the 
ERETIC method. Anal. Chem. 13, 2554-2557.

Aroulanda C., Lesot P., Merlet D., and Courtieu J. (2001) Structural ambiguities in bridged ring systems resolved using natural abundance deuterium NMR in chiral liquid crystals. J. Phys. Chem. A., 107, 10911-10918.

Bossard N., Jacob J., Le Milbeau C., Lallier-Vergès E., Terwilliger V.J. and Boscardin R. (2011) Variation in $\delta \mathrm{D}$ values of a single, species-specific molecular biomarker: a study of miliacin throughout a field of broomcorn millet (Panicum miliaceum L.). Rapid Com. Mass Spec. 25, $1-9$.

Bossard, N. (2013). Pertinence et calibration d'un nouveau marqueur paléohydrologique : Le rapport isotopique de l'hydrogène mesuré sur la miliacine. Ph.D. thesis, Université d'Orléans, Orléans, France.

Bossard N., Jacob, J. LeMilbeau C., Sauze J., Terwilliger V.J., Poissonnier B., and Vergès E. (2013). Distribution of miliacin (olean-18-en-3 $\beta$-ol methyl ether) in broomcorn millet (Panicum miliaceum), and other reputed potential sources. Consequences on the use of sedimentary miliacin as a tracer of millet. Org. Geochem. 63, 48-55.

Chikaraishi Y. and Narakoa H. (2003) Compound-specific $\delta D-\delta{ }^{13} \mathrm{C}$ analyses of n-alkanes extracted from terrestrial and aquatic plants. Phytochem. 63, 361-371.

Chikaraishi, Y., Naraoka H. and Poulson S.R. (2004) Hydrogen and carbon isotopic fractionations of lipid biosynthesis among terre (C3, C4 and CAM) and aquatic plants. Phytochem. 65, 13691381.

Chikaraishi Y., Tanaka R., Tanaka A. and Ohkouchi N. (2009) Fractionation of hydrogen isotopes during phytol biosynthesis. Org. Geochem. 40, 569-573.

Corbet B. (1980) Origine et transformation des triterpènes dans les sédiments récents. Ph.D. thesis, Université Louis Pasteur, Strasbourg, France, 106 p.

Cranwell P.A. (1984) Organic geochemistry of lacustrine sediments: triterpenoids of higher plant origin reflecting post-glacial vegetational succession. In Lakes Sediments and Environmental History (Eds. E.Y., Haworth and J.W.G. Lund). University Press, Leicester, pp. 69-92.

Das M. and Mahato S. (1983) Triterpenoids. Phytochem. 22, 1071-1085.

Dansgaard W. (1964) Stable isotopes in precipitation. Tellus 16, 436-468.

de Laeter J.R., Böhlke J.K., De Bièvre P., Hidaka H., Pieser H.S., Rosman K.J.R. and Taylo, P.D.P., (2003) Atomic weights of the elements. Pure Appl. Chem. 75, (6), 683-800.

Eglinton I.E. and Eglinton G. (2008) Molecular proxies for paleoclimatology. Earth and Planet. Sci. Let. 275, 1-16.

Feakins S.J. and Sessions A.L. (2010) Controls on the D/H ratios of plant leaf waxes in an arid ecosystem. Geochim. Cosmochim. Acta 74, 2128-2141. 
713

714

715

716

Freeman K. H., Boreham C.J., Summons R.E. and Hayes J. M. (1994) The effect of aromatization on the isotopic compositions of hydrocarbons during early diagenesis. Org. Geochem. 21, 10371049.

Gleixner G. and Mügler I. (2007) Compound-specific hydrogen isotope ratios of biomarkers: tracing climatic changes in the past. In Stable Isotopes as Tracers for Ecological Change (Eds. T. Dawson and R. Siegwolf). Terrestrial Ecology Series, Academic Press, Amsterdam, pp. 249266.

Hou J., D’Andrea W.J., McDonald D. and Huang Y. (2007) Hydrogen isotopic variability in leaf waxes among terrestrial and aquatic plants around Blood Pond, Massachussetts (USA). Org. Geochem. 38, 977-984.

HyperchemTM, Professional 6.1, Hypercube, Inc, 1115 NN 4th street, Gainsville, Florida, 32601, USA.

Itô H. (1934) The chemical investigation of some gramineae oils. J. Fac. of Agri., Hokkaido Imperial University, XXXVII, 1-40.

Jacob J., Disnar J.-R., Boussafir M., Sifeddine A., Albuquerque A.L.S. and Turcq B. (2005) Pentacyclic triterpene methyl ethers in recent lacustrine sediments (Lagoa do Caco, Brazil). Org. Geochem. 36, 449-458.

Jacob J., Disnar J.R., Boussafir M., Albuquerque A.L.S., Sifeddine A. and Turcq B. (2007) Contrasted distributions of triterpene derivatives in the sediments of Lake Caçó reflect paleoenvironmental changes during the last 20,000 years in NE Brazil. Org. Geochem. 38, 180-197.

Jacob J., Disnar J.-R., Arnaud F., Chapron E., Debret M., Lallier-Vergès E., Desmet M. and RevelRolland M. (2008a) Millet cultivation history in the French Alps as evidenced by a sedimentary molecule. J. Archaeol. Sci. 35, 814-820.

Jacob J., Disnar J.-R. and Bardoux G. (2008b) Carbon isotope evidence for sedimentary miliacin as a tracer of Panicum miliaceum (broomcorn millet) in the sediments of Lake le Bourget (French Alps). Org. Geochem. 39, 1077-1080.

Jacob J., Disnar J.-R., Arnaud F., Gauthier E., Billaud Y., Chapron E. and Bardoux G. (2009) Impacts of new agricultural practices on soil erosion during the Bronze Age in French Prealps. The Holocene 19, 241-249.

Jacob J., LeMilbeau C., Bossard N., Disnar J.R. and Billaud Y. (2011) Combined $\delta^{13} \mathrm{C}-\delta \mathrm{D}$ analysis of pentacyclic triterpenes and their derivatives. Studium Conference: "Hydrogen Isotopes as Environmental Recorders", 15-16 September 2011, Orléans, France.

Killops S.D., Raine J.I., Woolhouse A.D. and Weston R.J. (1995) Chemostratigraphic evidence of higher plant evolution in the Taranaki Basin, New Zealand. Org. Geochem. 23, 429-445. 
748

749

750

Lafon O., Lesot P., Merlet D. and Courtieu J. (2004) Modified z-gradient filtering as a new mean to obtain phased deuterium autocorrelation 2D-NMR spectra in oriented solvents. J. Magn. Reson. 171, 135-142.

Lavrieux M., Jacob J., Le Milbeau C., Zocatelli R., Masuda K., Bréheret J. G. and Disnar J. R. (2011) Occurrence of triterpenyl acetates in soil and their potential as chemotaxonomical markers of Asteraceae. Org. Geochem. 42, 1315-1323.

Lesot P., Merlet D., Lowenstein A. and Courtieu J. (1998) Enantiomeric Visualisation using ProtonDecoupled Natural Abundance Deuterium NMR in Poly( $\gamma$-benzyl-L-glutamate) Liquid Crystalline Solutions. Tetrahedron: Asymmetry 9, 1871-1881.

Lesot P., Baillif V. and Billault I. (2008) Combined analysis of four C-18 unsaturated fatty acids using Natural Abundance Deuterium 2D-NMR spectroscopy in chiral oriented solvents. Anal. Chem. 80, 2963-2972.

Lesot P. and Lafon O. (2008) Enantiomeric Analysis using Natural Abundance Deuterium 3D-NMR Spectroscopy in Polypeptide Chiral Oriented Media. Chem. Phys. Lett. 458, 219-222.

Lesot P. and Courtieu J. (2009) Natural abundance deuterium NMR spectroscopy: Developments and analytical applications in liquids, liquid crystals and solid phases. Prog. Nucl. Magn. Reson. Spectrosc. 55, 128-159.

Lesot, P., Serhan, Z. and Billault, I. (2011) Recent advances in the analysis of the site-specific isotopic fractionation of metabolites such as fatty acids using anisotropic natural abundance ${ }^{2} \mathrm{H}$ NMR spectroscopy: Application on conjugated linolenic methyl esters. Anal. Bioanal. Chem. 399, 1187-1200.

Lesot P., Serhan Z. Aroulanda C. and Billault I. (2012) Analytical contribution of NAD 2D-NMR spectroscopy in polypeptide mesophases to the investigation of triglycerides Magn. Reson. in Chem. 50, S2-S11.

Lesot P., Aroulanda C., Zimmermann, H. and Luz Z. (2015) Enantiotopic Discrimination in the NMR Spectrum of Prochiral Solutes in Chiral Liquid Crystals, Chem. Soc. Rev. 44, 2330.

Massou S., Nicolas C., Letisse F., Portais J.-C., Nmr-Based Fluoxomics: Quantitative 2D-NMR methods for isotopomers Analysis. Phytochemistry, 2007, 68, 2330-2340.

Liu W., Yang H. and Li L. (2006) Hydrogen isotopic composition of $n$-alkanes from terrestrial plants correlate with their ecological life form. Oecologia 150, 330-338.

Lohmann F. (1988) Aromatisations microbiennes de triterpènes végétaux. Ph.D. thesis, Université Louis Pasteur, Strasbourg, France.

Mahato S.B., Nandy A.K. and Roy G. (1992) Triterpenoids, Phytochem. 31, 2199-2249.

Mahato S.B. and Sen S. (1997) Advances in triterpenoid research, 1990-1994. Phytochem. 44, 11851236. 
783

784

785

786

787

788

789

790

791

792

793

794

795

796

797

798

799

800

801

802

803

804

805

806

807

808

809

810

811

812

813

814

815

816

Martin G.J. and Martin M.L., (1981) Deuterium labelling at the natural abundance level as studied by high field quantitative ${ }^{2} \mathrm{H}$ NMR, Tet. Lett. 22, 3525-3528.

Martin G.J., Zhang B.-L., Naulet N. and Martin M.L., (1986) Deuterium transfer in the bioconversion of glucose to ethanol studied by speific labeling at the natural abundance level. J. Am. Chem. Soc. 108, 5116-5122.

McInerney F.A., Helliker B.R. and Freeman K.H. (2011) Hydrogen isotope ratios of leaf wax nalkanes in grasses are insensitive to transpiration. Geochim. Cosmochim. Acta 75, 541-554.

Merlet D., Ancian B., Courtieu D. and Lesot P. (1999) Two-dimensional Deuterium NMR spectroscopy of chiral molecules oriented in a polypeptide liquid crystal: application for the enantiomeric analysis through natural abundance deuterium NMR. J. Am. Chem. Soc. 121, 5249-5258.

Motuzaite-Matuzeviciute G., Jacob J., Telizhenko S., Jones M.K. (2013) Miliacin in paleosoils from early Iron Age in Ukraine reveals paleofields of broomcorn millet. Archaeological and Anthropological Sciences, 1-8.

Ohmoto T., Ikuse M. and Natori S. (1970) Triterpenoids of the Gramineae. Phytochem. 9, 2137 2148.

Regnery J., Püttmann W., Koutsodendris A., Mulch A. and Pross J. (2013) Comparison of the paleoclimatic significance of higher land plant biomarker concentrations and pollen data: A case study of lake sediments from the Holsteinian interglacial. Org. Geochem. 61, 73-84.

Rullkötter J., Peakman T.M. and ten Haven, H.L. (1994) Early diagenesis of terrigenous triterpenoids and its implications for petroleum geochemistry. Org. Geochem. 21, 215-233.

Sachse D., Radke J. and Gleixner G. (2006) $\delta D$ values of individual n-alkanes from terrestrial plants along a climatic gradient - Implications for the sedimentary biomarker record. Org. Geochem. 37, 469-483.

Sarfati M., Lesot P., Merlet D. and Courtieu J. (2000) Theoretical and experimental aspects of enantiomeric differentiation using natural abundance multinuclear NMR spectroscopy in polypeptide liquid crystals. Chem. Commun. 21, 2069-2081.

Sauer P.E., Eglinton T.I., Hayes J.M., Schiemmelmann A., Sessions A.L. (2001) Compound-specific $\mathrm{D} / \mathrm{H}$ ratios of lipid biomarkers from sediments as a proxy for environmental and climatic conditions. Geochim. Cosmochim. Acta 65, 213-222.

Schwab V.F., Garcin Y., Sachse S., Todou G., Séné O., Onana J.-M., Houndong G. and Gleixner G. (2015) Effect of aridity on $\delta^{13} \mathrm{C}$ and $\delta \mathrm{D}$ values of $\mathrm{C} 3$ plant- and $\mathrm{C} 4$ graminoid-derived leaf wax lipids from soils along an environmental gradient in Cameroon (Western Central Africa) Org. Geochem. 78, 99-109. 
Serhan Z., Martel L., Billault I. and Lesot P. (2010) Complete determination of site specific bioenantiomeric excesses in linoleic acid using natural abundance deuterium 2D-NMR in polypeptide mesophase. Chem. Commun. 46, 6599-6601.

Sessions A.L., Burgoyne T.W., Schimmelmann A. and Hayes J.M. (1999) Fractionation of hydrogen isotopes in lipid biosynthesis. Org. Geochem. 30, 1193-1200.

Smetanina O.F., Kuznetzova T.A., Denisenko V.A., Pivkin M.V., Khudyakova Y.V., Gerasimenko A.V., Popov D.Y., Il'in S.G. and Elyakov G.B. (2001) 3 $\beta$-Methoxyolean-18-ene (miliacin) from the marine fungus Chaetomium olivaceum. Russ. Chem. Bull. 50, 2463-2465.

Smith F.A. and Freeman K.H. (2006) Influence of physiology and climate $\delta D$ of leaf wax n-alkanes from C3 and C4 grasses. Geochim. Cosmochim. Acta 70, 1172-1187.

Terwilliger V.J., Eshetu Z., Disnar J.R., Jacob J., Adderley W.P., Huang Y., Alexandre M. and Fogel M. (2013) Environmental changes and the rise and fall of civilizations in the northern Horn of Africa: an approach combining $\delta \mathrm{D}$ analyses of land-plant derived fatty acids with multiple proxies in soil. Geochim. et Cosmochim. Acta 111, 140-161.

Terwilliger V.J. and Jacob J. (2013) Introduction: Hydrogen isotopes as environmental recorders. Geochim. et Cosmochim. Acta 111, 1-4.

Trendel J. (1985) Dégradation des triterpènes dans les sédiments. Aspects photochimiques et microbiologiques. Ph.D. thesis, Université Louis Pasteur, Strasbourg, France, 126 p.

Wang Y., Sessions A.L., Nielsen R.J. and Goddard W.A. (2013) Equilibrium ${ }^{2} \mathrm{H} /{ }^{1} \mathrm{H}$ fractionation in organic molecules: III. Cyclic ketones and hydrocarbons. Geochim. et Cosmochim. Acta 107, $82-95$.

Wang Y.V., Larsen T., Leduc G., Andersen N., Blanz T. and Schneider R.R. (2013) What does leaf wax $\delta \mathrm{D}$ from a mixed $\mathrm{C} 3 / \mathrm{C} 4$ vegetation region tell us? Geochim. et Cosmochim. Acta 111, 128-139.

Wolff G.A., Trendel J.M. and Albrecht P. (1989) Novel Monoaromatic triterpenoids hydrocarbons occuring in sediments. Tetrahedron 45, 6721-6728.

Xu R., Fazio G.C. and Matsuda S.P.T. (2004) On the origins of triterpenoid skeletal diversity. Phytochem. 65, 261-291. 


\section{FIGURE CAPTIONS}

Figure 1: Structure of miliacin where $\mathrm{R}_{31}=-\mathrm{OMe}$ and gemanicol where $\mathrm{R}_{31}=-\mathrm{OH}$, together with the atomic numbering used and notation of rings (A to $\mathrm{E}$ ) and methyl groups (23 to 31).

Figure 2: $600.1 \mathrm{MHz}$ proton 1D-NMR spectrum of miliacin in $\mathrm{CDCl}_{3}(295 \mathrm{~K})$. The assignment of resonances of methyl groups is given in Table S-1, S-2 and S-3 in Appendix A.I of Supp. Info.). The peak marked by an asterisk $(\delta=1.24 \mathrm{ppm})$ is an unidentified impurity.

Figure 3: (a) Methyl region (Me31 not shown) of the $92.1 \mathrm{MHz}$ NAD tilted $Q$-resolved Fz 2D map of miliacin dissolved in $\mathrm{PBLG} / \mathrm{CHCl}_{3}$ and recorded at $295 \mathrm{~K}$. (b) $600 \mathrm{MHz}$ proton 1D spectrum of miliacin in $\mathrm{CHCl}_{3}$ plot at the horizontal same scale (in ppm). A lorenzian filtering $\left(\mathrm{LB}=1.5 \mathrm{~Hz}\right.$ ) has been applied in both spectral dimensions. On the $F_{1}$ and $F_{2}$ axes are shown the spectral 2D projections. Note the significant variations of peak intensity of ${ }^{2} \mathrm{H}$ doublets in $F_{1}$ dimension illustrating the enrichment/depletion in deuterons.

Figure 4: Series of four NAD 1D sub-spectra extracted from the tilted $Q$-resolved $\mathrm{Fz} 2 \mathrm{D}$ map showing the nine methyl groups of miliacin along with their assignments (see also Fig. S-9). Each sub-spectrum is plotted with the same amplitude of noise. Note the variation of peak intensity of ${ }^{2} \mathrm{H}$ doublets. The variations observed reveal the differences of $(\mathrm{D} / \mathrm{H})$ for each site.

Figure 5: 3D view of the minimal energy conformation of miliacin calculated with Hyperchem 3.0 software. A semi-empirical quantum chemistry methods based on the Hartree-Fock formalism (Austin Model 1 or AM1) has been used for modeling the molecule. The minimal energy was found at $-8177.99 \mathrm{~kJ} / \mathrm{mol}$. Except for ring E distorted by the double bond, all other cycles have adopted a chair conformation. Note the difference of orientation axes of $\mathrm{C}-\mathrm{CH}_{3}$ vectors for Me23 and Me30 (close to the median horizontal molecular plan) compared to Me24 to Me29 (see also Fig. S-9 in Appendix A.II of Supp. Info.).

Figure 6: Variation of (a) $(\mathrm{D} / \mathrm{H})$ ratios in $\mathrm{ppm}$ and $(\mathrm{b}) \delta \mathrm{D}$ in $\%$ for each methyl group of miliacin when $(\mathrm{D} / \mathrm{H})_{\mathrm{Me} 31}$ is evaluated by the two-step NAD NMR approach. Excluding the exogenous methyl group 31, note the (inverted) quasi-symmetrical bell shape of both plots.

Figure 7: Synthetic pathway leading to miliacin. Modified from Sachse et al. (2012).

Figure 8: Potential diagenetic pathways of pentacyclic triterpenes (here starting from $\alpha$-amyrin) illustrating the loss of hydrogen atoms related to methyl groups, methylene/methine. Modified from Wolff et al. (1989). 